\title{
A TUTELA DO DIREITO DE PROPRIEDADE NO ESTADO DE DIREITO: OS PADRÕES EUROPEUS DE RESPEITO AOS DIREITOS FUNDAMENTAIS
}

\section{THE PROTECTION OF PROPERTY RIGHTS IN THE RULE OF LAW: EUROPEAN STANDARDS OF RESPECT FOR FUNDAMENTAL RIGHTS}

\author{
Patrícia Silva Cardoso ${ }^{1}$ \\ Francesca Benatti ${ }^{2}$
}

\section{Resumo}

O objetivo do presente artigo é explorar o reconhecimento e a proteção da propriedade privada como direito fundamental e sua relação com a noção de garantia da propriedade nas constituições democráticas. A conexão entre nível de tutela conferida ao direito de propriedade e a democracia se tornou um critério para avaliar o estado da democracia de um país em diversos organismos internacionais. Tendo em vista que a garantia propriedade privada é considerada um importante elemento de proteção do indivíduo contra o Estado, pretende-se aprofundar as construções teóricas que associam a tutela da propriedade privada a um maior nível de desenvolvimento democrático. Com tal intuito, serão analisados os padrões do Estado de Direito estabelecido na Europa, marcado pela democracia e pelo respeito aos direitos fundamentais do indivíduo, com especial ênfase à tutela da propriedade estabelecida pelos órgãos do Conselho da Europa, como a Comissão de Veneza para a Democracia através do Direito e a Corte Europeia de Direitos do Homem.

Palavras-chave: propriedade privada; democracia; garantia constitucional; Estado de Direito.

\begin{abstract}
The essay analyses the recognition and protection of private property as a fundamental right and it focuses on its relation to the notion of constitutional guarantee of property established in the constitutions of democratic countries. The connection between the level of protection of property rights and democracy and its protection has become the criterion for assessing the state of a country's democracy in various international bodies. Considering that the guarantee of private property is considered an important element of protection of the individual against the State, we intend to deepen the theoretical constructions that associate the tutelage of private property with a higher level of democratic development. To this end, the essay examines the standards of the rule of law established in Europe, marked by democracy and respect for the fundamental rights of the individual, with particular emphasis on the protection of property established by Council of Europe bodies such as the Venice Commission for the Democracy through Law and the European Court of Human Rights
\end{abstract}

Keywords: private property, democracy, constitutional guarantee, Rule of Law

\footnotetext{
${ }^{1}$ Professora de Direito Civil da Universidade Federal Fluminense (UFF) - Brasil. Doutora em Direito pela Universidade do Estado do Rio de Janeiro (UERJ), em co-tutela com a Università degli Studi di Roma - La Sapienza. E-mail: patriciacardoso@id.uff.br

2 Professora de Direito Privado Comparado da Università degli Studi di Padova - Itália. Doutora em Direito Privado Comparado pela Università degli Studi di Pavia. E-mail: francesca.benatti@unipd.it
} 


\section{INTRODUÇÃO}

O direito de propriedade privada é atualmente reconhecido, ainda que com limites determinados pelo interesse social, ${ }^{3}$ pelas Constituições de quase todos os Estados e pela Cartas internacionais. Todavia, a sua concreta conformação e proteção são influenciadas por números fatores de natureza social, filosófica, política, jurídica e econômica. Inobstante a diferença entre a sua qualificação no direito constitucional, internacional e privado, para o jurista impõe-se, sobretudo, a necessidade de uma definição que não pode ser atribuída à tradição. ${ }^{4}$

Salienta Pugliatti que a utilidade do conceito legal de propriedade não pode ser negada - assim como a de outros conceitos gerais e, de certo modo, tradicionais - pois são o resultado da conciliação de exigências teóricas e práticas que são abrangidas pela sistemática dos conceitos criados pelo Direito Positivo. Tais conceitos tiveram a sua utilidade e legitimidade testadas no suceder dos anos e das gerações, precisamente a partir do emprego e do bom uso no suceder dos anos e das gerações. ${ }^{5}$

Cabe ainda frisar que o direito de propriedade não é concebido de modo isolado, mas dentro do sistema de direitos reais. Contudo, este é também um símbolo, pois as instituições proprietárias " $n a ̃ o$ apenas regulam a complexidade da interação humana, mas também moldam o caráter dessas interações" ${ }^{6}$

O modo como a lei regula o direito de propriedade revela os valores mais profundos de uma sociedade, pois não se refere apenas à alocação de recursos escassos, à informação ou à complexidade, tratando-se de "promover "a vida, a liberdade e a busca da felicidade". ${ }^{7}$ A propriedade refere-se à ordem social, pois reflete a concepção do que significa viver numa sociedade livre e democrática que trata cada pessoa com igual preocupação e respeito. Em tal perspectiva, o direito de propriedade é estreitamente ligado com a ideia de democracia. ${ }^{8}$

\footnotetext{
${ }^{3}$ Pode-se citar como exemplos as Constituições brasileira e italiana.

${ }^{4}$ A observação aplica-se aos ordenamentos de Civil Law, baseados nas categorias do Direito Romano. Na Common Law, a law of property tem origem no sistema feudal.

${ }^{5}$ PUGLIATTI, Salvatore. La proprietà nel nuovo diritto, Milano: Giuffrè, 1954, p. 147.

${ }^{6}$ SINGER, Joseph W. Property as the law of Democracy, In: Duke Law Journal, vol. 63, n. 6, 2014, p. 1299.

${ }^{7}$ Idem. p. 1299.

8 Note-se que a mesma noção de democracia seja hoje complexa e de difícil definição. Sobre uma ilustração dos diversos modelos ver: HELD, David. Models of Democracy. Cambridge/Malden: Polity Press, 2006.
} 
PROPRIEDADE PRIVADA E DEMOCRACIA: UMA APROXIMAÇÃO AO DEBATE.

O debate sobre o papel do desenvolvimento econômico na instauração e na consolidação de uma democracia é atual e polêmico. Indaga-se sobre a relação que se estabelece entre estes dois vetores: se o desenvolvimento econômico gera a democracia ou se, ao contrário a democracia constitui a base necessária para o progresso; ou ainda, se é possível configurar uma diversa correlação não abrangida pelas duas primeiras.

A questão proposta se coloca numa linha teórica distinta da indagação sobre a natureza do sistema econômico, todavia, a reflexão sobre o tema implica uma breve digressão sobre o modelo preferível para incentivar o crescimento. De fato, desde Aristóteles tem-se frisado que apenas uma situação de bem-estar pode garantir uma participação ativa dos cidadãos na vida pública e impedir a tomada de poder por parte de oligarquias e ditadores. ${ }^{9}$

A partir dos anos sessenta do século passado, estudos empíricos procuraram demonstrar que o desenvolvimento econômico é um fator facilitador de transições democráticas bem-sucedidas em países anteriormente autoritários. ${ }^{10}$ Segundo Daniel Lerner, expoente dos estudos sobre o desenvolvimento no período supramencionado, a evolução geralmente ocorre em três fases. ${ }^{11}$ A primeira inclui a urbanização progressiva, na qual emergem os elementos estruturais da sociedade industrializada. Posteriormente, como consequência, há o crescimento da alfabetização e da cultura, que caracterizam a segunda fase, até que se caminhe para a exigência de uma informação de massa, próxima etapa. Apenas na última fase pode-se instaurar um sistema democrático.

As razões para tal raciocínio são inúmeras. Inicialmente, entende-se que a industrialização determina uma difusão, até mesmo para fora do Estado e de seus órgãos, de riquezas e de poderes, ${ }^{12}$ o que traz mudanças na estrutura da sociedade e nos seus valores.

\footnotetext{
9 LIPSET, Seymour Martin. Some Social Requisites of Democracy: Economic Development and Political Legitimacy. In: The American Political Science Review. vol. 53, n. 1, march.,1959, p. 69. Disponível em: <http://scholar.harvard.edu/files/levitsky/files/lipset_1959.pdf>. Acesso em: 03 abr. 2017.

10 Observe-se-se que não é suficiente que haja uma transição democrática, mas também que essa gere uma democracia estável. Cf. KAPSTEIN, Ethan B; CONVERSE, Natan. Why Democracies Fail. In: Journal of Democracy, vol. 19, $n^{\circ}$. 4, october, 2008, p. 57. Disponível em: <http://cddrl.fsi.stanford.edu/sites/default/files/19.4.kapstein.pdf>. Acesso em: 03 abr. 2017.

${ }^{11}$ LERNER, Daniel. The passing of traditional society, Glencoe: Free Press, 1958, p. 60 ss.

12 HUNTINGTON, Samuel P. The Third Wave. Democratization in the Late Twentieth Century. Oklahoma: University of Oklahoma Press, 1993, p. 65.
} 
Nota-se um aumento da confiança, da competência e da satisfação em relação à própria vida, ${ }^{13}$ estreitamente conexo a novos desejos e aspirações, de natureza não exclusivamente material. As mudanças repercutem ainda numa tendência ao aumento dos níveis de educação da população, que é um outro fator considerado central para a democratização.

É importante notar que segundo tal perspectiva o desenvolvimento econômico não deve ser considerado de modo isolado ou como única variável condicionante, uma vez que todos os seus aspectos - industrialização, urbanização, saúde e educação - estão ligados de modo tão íntimo que constituem um só fator, que encontra expressão política na democracia. ${ }^{14}$

A partir da obra de Schumpeter, ${ }^{15}$ ao lado do debate sobre o papel do desenvolvimento econômico, a análise passou a estar voltada para a compatibilidade do capitalismo e do socialismo com a democracia. Se no pensamento de Kelsen ${ }^{16}$ estes não se ligam essencialmente a um determinado sistema político, atualmente parece prevalecer a tese que considerada relevante o papel do mercado ${ }^{17}$ na facilitação e garantia de certos direitos e liberdades que estão na base de um Estado democrático.

Entre tais direitos e liberdades assume particular relevância a tutela do direito de propriedade, que constitui um pressuposto fundamental do crescimento e do progresso. A assertiva é corroborada pelas análises de dados empíricos que demonstram que a intensidade da tutela dada ao direito de propriedade costuma ter maior influência na taxa de crescimento num país do que as próprias características do seu sistema político. ${ }^{18}$

\footnotetext{
${ }^{13}$ INKELES, Alex; DIAMOND, Larry. Personal Development and National Development: A Cross-National Perspectives. In: SZALAI, Alexander; ANDREWS, Frank M. (eds.).The Quality of Life: Comparative Studies, London: Sage Publications, 1980, p. 83.

${ }^{14}$ LIPSET, Seymour Martin. Political Man. The Social Bases of Politics, New York: Doubleday \& Company, 1960, p. 41; WUCHERPFENNING, Julian; DEUTSCH, Franziska. Modernization and Democracy: Theories and Evidence Revisited. In: Living Reviews in Democracy, 2009. p. 7: "Democracy does not come about randomly, and for democracy to be stable it must come about from within, since it is the socio-economic conditions which create and maintain an environment for stable and enduring democracies. Thus, for an effective promotion of democracy, as it is part of many foreign policies, socio-economic development must be a central component." Disponivel em: < http://idwebhost-20283.ethz.ch/index.php/Ird/article/viewFile/Ird-2009-4/14>. Acesso em: 03 abr. 2017.

${ }^{15}$ SCHUMPETER, Joseph A. Capitalism, Socialism and Democracy. New York \& London: George Allen \& Unwin Publishers, 2011, p. 131 ss.

${ }^{16}$ KELSEN, Hans. I fondamenti della democrazia. Bologna: II Mulino,1955, p. 258.

${ }^{17}$ Em parte, o tema migrou para os limites que devem ser impostos ao mercado.

18 LEBLANG, David A. Property Rights Democracy and Economic Growth. In: Political Research Quarterly. vol. 49, Issue 1, 1996, p. 5 ss.
} 
Enquanto a importância do direito de propriedade na geração do progresso é conhecida e encontra elaboração na obra de Adam Smith, ${ }^{19}$ a sua correlação com a democracia é bastante recente..$^{20}$ Cabe frisar que no século XIX, era opinião corrente que a instituição do sufrágio universal, a criação dos sindicatos e a abertura a um sistema democrático teriam gerado uma lesão no direito de propriedade, que se enquadrava num contexto elitista. ${ }^{21}$ Todavia, a tese foi desmentida pela evolução histórica sucessiva, pois a democracia não destruiu o direito de propriedade, ao contrário, trouxe sua difusão, de modo que a sua tutela se tornou um critério para valorar o estado da democracia de um país. ${ }^{22}$

Isto ocorre por causa da natureza dúplice do direito de propriedade, ${ }^{23}$ cujo caráter foi assim ressaltado por Blackstone: "não há nada que estimule tanto a imaginação e os afetos do gênero humano como a propriedade". ${ }^{24}$ Tal direito pode ser considerado ao mesmo tempo uma relação econômica e um direito fundamental que serve como fundamento para outras liberdades individuais. Daí a afirmação de que a propriedade estaria situada em uma zona cinzenta, no limite entre o privilégio e a liberdade. ${ }^{25}$

Neste particular, é salutar a constatação de James Madison:

"this term in its particular application means "that dominion which one man claims and exercises over the external things of the world, in exclusion of every other individual." In its larger and juster meaning, it embraces everything to which a man may attach a value and have a right; and which leaves to everyone else the like advantage. In the former sense, a man's land, or merchandize, or money is called his property. In the latter sense, a man has a property in his opinions and the free communication of them." 26

\footnotetext{
${ }^{19}$ SMITH, Adam. An Inquiry into the Nature and Origins of the Wealth of Nations. New York: Edwin Cannan MA. LLD, 1937, p. 862: "Commerce and manufactures can seldom flourish long in any state which does not enjoy a regular administration of justice, in which people do not feel themselves secure in possession of their property, in which the faith of contracts is not supported by the law".

${ }^{20}$ Sobre a natureza do direito de propriedade, a teoria lockiana é uma referência fundamental. LOCKE, John. Segundo Tratado Sobre o Governo Civil. Tradução: Magda Lopes e Marisa Lobo da Costa. São Paulo: Vozes, 2006.

${ }^{21}$ A reconstrução é de: PRZEWORSKI, Adam; LIMONGI, Fernando. Political Regimes and Economic Growth. In: The Journal of Economic Perspectives, vol. 7, nº. 3, 1993, p. 51 ss.

${ }^{22}$ Apesar de o reconhecimento do direito de propriedade estar garantido por muitas Cartas de direitos internacionais e pela grande parte das Constituições, a tutela concedida a tal direito pode variar, uma vez que o conceito pode ser concebido de maneiras diversas, que englobam desde um núcleo essencial até uma tutela mais geral.

${ }^{23}$ Diante da polissemia do termo, Ferrajoli distingue entre o direito abstrato de tornar-se proprietário e dispor do bem do conceito concreto de propriedade sobre este ou aquele bem. (FERRAJOLI, Luigi. Diritti fondamentali, un dibattito teórico. Roma-Bari: Laterza, 2001, p. 13

${ }^{24}$ BLACKSTONE, William. Commentaries on the Law of England II, London: George Sharswood, 1809, p. 2.

${ }^{25}$ BRITO, Miguel Nogueira de. Propriedade privada: entre o privilégio e a liberdade. Lisboa: FFMS, 2010.

${ }^{26}$ E conclui: "if the United States mean to obtain or deserve the full praise due to wise and just governments, they will equally respect the rights of property, and the property in rights: they will rival the
} 
A concepção de propriedade como direito humano encontrou reconhecimento significativo no protocolo 1 da Convenção Europeia de Direitos do Homem. ${ }^{27}$ Na visão dos seus redatores, a tutela da propriedade é um elemento fundamental da rule of law, e tal aproximação foi confirmada pela jurisprudência da Corte Europeia de Direito do Homem (doravante Corte $E D H$ ), que atribuiu a tal direito uma dimensão diversa e mais ampla do que a trazida pelos ordenamentos nacionais. A sua tutela engloba também os direitos de crédito e todas as expectativas legítimas e razoáveis dos cidadãos. Neste sentido, é paradigmática a evolução da proteção conferida à propriedade intelectual pela Corte. ${ }^{28}$

As decisões da Corte EDH influenciaram as jurisdições de outros ordenamentos, não apenas europeus, que progressivamente reconheceram o status de direito humano à propriedade. Recentemente, a Suprema Corte Indiana, ao julgar um caso de ausência de compensação por expropriação de propriedade rurais, dispôs: “

"Tendo sido o direito de propriedade elevado ao nível de direito humano, é próprio de cada indivíduo e, assim, deve ser reconhecido com veneração, não podendo de nenhum modo, ser diminuído ou banalizado pela adoção de disposições indiferentes ou desdenhosas por parte de quem quer que seja, sobretudo o Estado, na sequência de um procedimento expropriatório". ${ }^{29}$

E prosseguiu afirmando que se "anteriormente os direitos humanos existiam por afirmação do direito dos individuais à saúde, aos meios de subsistência, moradia e trabalho, estes começaram a assumir uma natureza multiforme", tanto é verdade que o direito de propriedade é incluído no rol dos direitos humanos. ${ }^{30} \mathrm{Na}$ decisão da Corte, contata-se de modo

government that most sacredly guards the former; and by repelling its example in violating the latter, will make themselves a pattern to that and all other governments." (MADISON, James. Property. In: National Gazette. March 29, 1792. Disponível em: <https://thf_media.s3.amazonaws.com/2011/pdf/FP_PS02.pdf >. Acesso em: 03 abr. 2017).

27 Cf. BENATTI, Francesca; CARDOSO, Patrícia Silva. A garantia constitucional da propriedade privada como garantia de posições jurídicas: as experiências portuguesa e italiana. In: VEIGA, Fabio da Silva; GONÇALVES, Rubén Miranda. O Direito Constitucional e o seu papel na construção do cenário jurídico global. Barcelos: Portugal, 2016, pp. 49-58.

${ }^{28}$ Cf. HELFER, Laurence R. The New Innovation Frontier? Intellectual Property and the European Court of Human Rights. In: Harvard International Law Journal. vol. 49, n. 1, 2008, p. 01.

${ }^{29}$ Lalaram \& Ors vs Jaipur Devt.Auth.\& Anr on 1 December. Supreme Court of India. Disponível em: < https://indiankanoon.org/doc/168139441/>. Acesso em: 03 abr. 2017.

${ }^{30}$ É interessante notar que a Corte Indiana faz menção à influência da Corte EDH em seus próprios julgados: "But what is commendable is that the dimensions of human rights have widened so much that now property dispute issues are also being raised within the contours of human rights. With the expanding jurisprudence of the European Courts of Human Rights, the Court has taken an unkind view to the concept of adverse possession." Lalaram \& Ors vs Jaipur Devt.Auth. \& Anr on 1 December. Supreme Court of India. Disponível em: <https://indiankanoon.org/doc/168139441/>. Acesso em: 03 abr. 2017. 
implícito a necessidade de uma garantia efetiva do direito de propriedade, sem a qual todos os demais direitos são ilusórios. ${ }^{31}$

O direito de propriedade possui uma inegável natureza econômica e a doutrina reconhece a importância da sua tutela na geração de desenvolvimento. ${ }^{32}$ Cabe frisar que nos estudos econômicos, tem-se observado uma certa mudança de panorama; de pesquisas concentradas em modelos abstratos, isto é, sem instituições e com property rights abstratos perfeitos, passou-se às abordagens institucionais, centradas nos custos da criação, especificação e reforço dos direitos de propriedade concretamente colocados.

Contudo, duas ponderações devem ser feitas. Atualmente, constata-se a diversidade dos bens ${ }^{33}$ objeto do direito de propriedade, o que torna difícil a definição de paradigma unitário para tal direto, tratando-se de uma categoria fluida e em continua evolução. ${ }^{34}$ Além disso, não existem critérios universalmente aceitos ${ }^{35}$ para medir o grau de proteção conferido à propriedade, o que frequentemente gera resultados inconciliáveis e de complexa avaliação. ${ }^{36}$

É claro que a eficaz proteção da propriedade e dos direitos reais em geral não deve se tornar uma panaceia ${ }^{37}$ para todos os problemas de baixo crescimento e de poucos

\footnotetext{
${ }^{31}$ Em igual sentido, decisão da Suprema Corte dos Estados Unidos da América. Cfr. Lynch v. Household Finance Corp., 405 U.S. 538, 552 (1972): "The dichotomy between personal liberties and property rights is a false one .... In fact, a fundamental interdependence exists between the personal right to liberty and the personal right in property. Neither could have meaning without the other. That rights in property are basic civil rights has long been recognized."). Disponível em: < https://supreme.justia.com/cases/federal/us/405/538/>. Acesso em: 03 abr. 2017.

32 NORTH, Douglas C; THOMAS, Robert Paul. The Rise of the Western World: A New Economic History. New York: Cambridge University Press,1973.

${ }^{33}$ GAMBARO, Antonio. I beni, In: Trattato di Diritto Civile Commentato. diretto da Cicu-MessineoMengoni, continuato da P. Schlesinger, Milano: Giuffrè, 2012.

${ }^{34}$ FRYE, Timothy. Original Sin, Good Works, And Property Rights In Russia. In: World Politics. n. 58, July 2006, p. 479 ss.

${ }^{35}$ A doutrina tem utilizado fatores formais (o modelo de direitos reais adotado, a eficiência das Cortes, do aparato administrativo e das forças de polícia) e informais (o papel das redes de contatos, a confiança, o capital social). Cf. FRYE, Timothy. Credible commitment and Property Rights: Evidence from Russia. Disponível em:

http://www1.worldbank.org/publicsector/politicaleconomy/FryeCredibleCommitment.pdf/>. Acesso em: 03 abr. 2017.

${ }^{36}$ Cf. FRYE, Timothy. Original Sin, Good Works, And Property Rights In Russia. In: World Politics, n. 58, July 2006, p. 479 ss.

${ }^{37}$ Cf. BESLEY, Timothy. Property Rights and Investment Incentives: Theory and Evidence from Ghana. In: The Journal of Political Economy, vol. 103, $n^{\circ}$. 5, Oct., 1995, pp. 903-937. Disponível em: $<$ https://www.princeton.edu/rpds/papers/Besley_Property_Rights_and_Investment_Incentives_JPE1995. pdf>. Acesso em: 03 abr. 2017.
} 
investimentos. Todavia, direitos reais bem definidos e garantidos influenciam o desenvolvimento econômico através de quatro modos ou canais: ${ }^{38}$

a. A eficiência, que permite que os bens sejam utilizados por aqueles que mais os valorizam e possam empregá-los de modo mais produtivo;

b. A segurança, que aumenta os investimentos, pois as empresas e os indivíduos tutelados diante de expropriações arbitrárias ${ }^{39}$ encontram maior incentivo para investirem de modo contínuo e assim geram um ciclo positivo de investimentos; ${ }^{40}$

c. A redução de custos, uma vez que os recursos não destinados a proteger os property rights, que já estão garantidos, podem ser usados com outro escopo;

d. A facilitação dos negócios: os bens objetos destes direitos podem funcionar como garantia para outras operações e aumentar a produtividade geral do sistema. ${ }^{41}$

O papel dos direitos reais no progresso econômico pode ser também demonstrado pela experiência chinesa, país no qual o progressivo reconhecimento dos property rights culminou na adoção da Lei de Propriedade em 2007 (Property Law), motivada pela percepção de que a ausência de uma tutela proprietária mínima inviabilizaria o crescimento econômico. ${ }^{42}$ Contudo, diante da natureza não democrática do sistema, os escassos mecanismos de tutela dos direitos de propriedade implementados pela lei não chegaram a constituir uma reforma efetiva no regime, o qual continuou a prever, por exemplo, a prática das expropriações ilegais.

Atualmente, no China o debate está concentrado na possibilidade de estender o direito de propriedade a terrenos, a fim de criar incentivos e contribuir para resolver as dificuldades e insatisfações crescentes da classe média. Ainda que sejam questionáveis os problemas de

38 BESLEY, Timothy; GHATAK, M. Property rights and economic development, In: RODRIK, Dani; ROSENZWEIG, Mark (eds.). Handbook of Development Economics. North-Holland: Elsevier BV, 2009, p. 4525 ss.

39 DEMSETZ, Harold. Toward a Theory of Property Rights. In: The American Economic Review, vol. 57, $n^{\circ}$. 2, Papers and Proceedings of the Seventy-ninth Annual Meeting of the American Economic Association, may, 1967, pp. 347-359. Disponível em: < http://econ.ucsb.edu/ tedb/Courses/Ec100C/Readings/Demsetz_Property_Rights.pdf >. Acesso em: 03 abr. 2017; ALCHIAN, Armen; DEMSETZ, Harold. The Property Rights Paradigm. In: The Journal of Economic History, vol. 33, no. 1, The Tasks of Economic History, mar.,1973, pp. 16-27. Disponível em: <http://links.jstor.org/sici?sici=0022-0507\%28197303\%2933\%3A1\%3C16\%3ATPRP\%3E2.0.CO\%3B2-A>. Acesso em: 03 abr. 2017

${ }^{40}$ A segurança dos direitos reais determina uma diminuição dos custos de transação (transaction costs) dos contratos de venda e locação.

${ }^{41}$ Tal tese é amplamente desenvolvida por: DE SOTO, Hernando. II mistero del capitale. Milano: Garzanti, 2001.

42 BENATTI, Francesca. Le situazioni di appartenenza in Cina: vecchie e nuove sfide. In: Rassegna di Diritto Civile. $n^{\circ} .1$ 2015, p. 207 ss. 
legitimidade do sistema que poderia vir a ser criado, parte da doutrina vê nestes movimentos, somados à estagnação econômica, a possiblidade de uma mudança política do país. ${ }^{43}$

Direito de propriedade e democracia estão interligados de dois modos diversos. A propriedade como direito humano é um componente essencial de uma democracia verdadeira, mas o seu reconhecimento e tutela são também essenciais ao mercado e geram o desenvolvimento necessário à instauração e manutenção da democracia. ${ }^{44}$ Tal visão leva a considerar que a longo prazo um sistema democrático estável com direitos reais seguros possa crescer mais que uma autocracia ou democracia não liberal..$^{45}$

Mais corretamente, a relação entre tais vetores é considerada indireta, ${ }^{46}$ a depender das circunstâncias internas e externas ao sistema. Segundo Fukoyama, o mercado não gera uma pressão direta para a democracia, sendo compatível com muitas formas de autoritarismo, salvo com o totalitarismo comunista; porém, o autor reconhece que o capitalismo é mais eficiente para gerar desenvolvimento econômico que o socialismo, "e comumente mais favorável para gerar rápidas mudanças socioeconômicas que favorecem a emergência de uma democracia estável". ${ }^{47}$

Para o autor, o "o elo perdido" ${ }^{48}$ que liga a democracia ao capitalismo é constituído pelos princípios de reconhecimento universal e igualdade, nascidos com o cristianismo e posteriormente secularizados, que estão na base no desejo de democracia ${ }^{49}$. O desenvolvimento e a modernização, sobretudo capitalista, ${ }^{50}$ determinam a superação das

\footnotetext{
${ }^{43}$ MINXIN PEI. Transition in China? More Likely than You Think. In: Journal of Democracy, vol. 27, $n^{\circ} .4$, october.2016, pp. 5-19.

44 BARRO, Robert G. Democracy and growth: In: Journal of Economic Growth. n¹, mar. 1996. p. 1 ss. Disponível em: <http://faculty.nps.edu/relooney/BarroDemocracy.pdf>. Acesso em: 03 abr. 2017.

45 "But in the secure democracy with predictable succession of power under the rule of law, the adjudication and enforcement of individual rights is not similarly short-sighted. Many individuals in the secure democracies confidently make even very-long-term contracts, establish trusts for greatgrandchildren, and create foundations that they expect will last indefinitely and thereby reveal that they expect their legal rights to be secure for the indefinite future". (OLSON, Mancur. Dictatorship, Democracy, and Development. In: The American Political Science Rev., vol. 87, n. 3. Sep.,1993 p. 572. Disponível em: <http://www.svt.ntnu.no/iss/Indra.de.Soysa/POL3503H05/olson.pdf>. Acesso em: 03 abr. 2017).

${ }^{46}$ Cf. FRIEDMAN, Milton. Capitalism and Freedom. Chicago: University of Chicago Press, 1962, p. 10. O autor observa que: "clearly it is not a sufficient condition...It is clearly possible to have economic arrangements that are fundamentally capitalist and political arrangements that are not free".

47 FUKUYAMA, Francis. Capitalism \& Democracy: The missing link. In: Journal of Democracy, vol. 3, $n^{\circ} .3$, July 1992, p. 108. Disponível em: <https://muse.jhu.edu/article/225517/pdf>. Acesso em: 03 abr. 2017.

48 FUKUYAMA, Francis. Op. cit. p. 108.

${ }^{49}$ Idem.

50 "More comfortable and more certain, however, is the reason why capitalism is necessary for democracy: It provides the social space within which individuals, groups, and entire institutional
} 
barreiras sociais, favorecendo a mobilidade: as desigualdades são percebidas como fluidas e não dependem tanto do status, quanto da educação e dos esforços individuais. ${ }^{51}$

Para Fukoyama, a questão coliga-se também com o surgimento e a manutenção da classe média ${ }^{52}$ e sua participação no processo democrático. ${ }^{53}$ A existência e homogeneidade de uma classe média em uma democracia teria papel significativo na estabilização social, uma vez que fortes desigualdades sociais podem causar instabilidade, sobretudo nos ordenamentos sujeitos à transição democrática ou nas democracias jovens. Os institutos jurídicos nos quais se manifesta a afirmação da classe média - e que são necessários para a sua manutenção e para sua progressiva difusão - são o contrato e a propriedade.

A doutrina que evidencia uma ligação imprescindível entre a classe média e a democracia também antevê no declínio atual da primeira uma majoração do risco para a segunda. ${ }^{54}$ As razões da crise são evidenciadas na liberalização e na globalização dos mercados,

complexes can develop independent of state control. To use a term that has lately returned to fashionable usage, capitalism creates space and opportunity for civil society. Conversely, the empirical correlation between socialism and dictatorship can be explained precisely by the absence of such social space in a socialist system". BERGER, Peter. The uncertain triumph of democratic capitalism. In: Journal of Democracy, vol. 3, n. 3, July 1992, p. 12. Disponível em: <https://muse.jhu.edu/article/225511/pdf>. Acesso em: 03 abr. 2017, pp. 7-16.

${ }^{51}$ F. FUKUYAMA, Capitalism \& Democracy: The missing link. Op. cit. p. 109.

52 HUNTINGTON, Samuel. The third wave. Democratization in the Late Twentieth Century. Op. cit. p. 65: "The correlation between wealth and democracy implies that transitions to democracy should occur primarily in countries at the middle levels of economic development. In poor countries democratization is unlikely; in rich countries it has already occurred. In between there is a political transition zone; countries in that particular economic stratum are most likely to transit to democracy and most countries that transit to democracy will be in that stratum."

${ }^{53}$ Nesta perspectiva, o mercado é apontado como um instrumento que contribui para o nascimento da classe média. Sustenta-se que, enquanto o capitalismo surge espontaneamente das condições econômicas e políticas, a democracia é a consequência de uma burguesia que se opõe ao sistema feudal, expressa hoje na classe média. Nos casos em que a industrialização é controlada pelo Estado, este deverá eventualmente ser confrontado com a classe média que indiretamente favoreceu. Sobre o tema: KYUNWON, Kim. Marx, Schumpeter and the East-Asian experience. In: Journal of Democracy, vol. 3, $\mathrm{n}^{\circ}$. 3, July,1992, p. 29. Ver ainda o pronunciamento de Zhao

Ziyang, líder do Partido Comunista Chinês, o qual deixou após as desordens ocorridas na Praça Tiananmen: "I used to think that so long as we did well in reforming the economy and people's living standards went up, then the people would be satisfied and society would be stable. But as I later discovered, this is not the way things are. After living standards and cultural levels have been raised, the people's sense of democracy and sense of political participation will grow stronger. If the building of democracy and a legal system fails to keep up, then society will not be stable". Cf.

ROWEN, Henry. The tide underneath the 'third wave'. In: Journal of Democracy, vol. 6, $\mathrm{n}^{\circ} 1$, January 1995, p. 53-54. Acesso em:< https://muse.jhu.edu/article/16659>. Disponível em: 08 abr. 2017; BERGER, Peter. The uncertain triumph of democratic capitalism. In: Journal of Democracy, vol. 3, nº. 3, July 1992, p. 12. Disponível em: < https://muse.jhu.edu/article/16659>. Acesso em: 03 abr. 2017.

${ }^{54}$ FUKUYAMA, Francis. Future of History: Can Liberal Democracy Survive the Decline of the Middle Class? In: Foreign Affairs, vol. 91, $\mathrm{n}^{\circ}$. 1, jan/febr., 2012, p. 53. Disponível em: < http://www.jstor.org/stable/23217147>. Acesso em: 03 abr. 2017. 
que comportam novos equilíbrios políticos, sociais e econômicos. Por outro lado, a esta tese que considera determinante o papel da classe média na consolidação da democracia, objeta-se que os eventos que levaram à constituição das democracias liberais ou a casos de autoritarismo foram também apoiados por tal classe social. ${ }^{55}$

A temática é complexa, seja pela diversidade histórica, econômica, social e política dos países que sofreram estes fenômenos, seja pela dificuldade de definir com clareza a noção de democracia, entre os seus aspectos procedimentais e substanciais. Nem sempre "one size fits it all'; todavia, algumas reflexões podem ser propostas.

O fato de em alguns Estados a classe média apoiar regimes autoritários encontra uma possível motivação nas exigências de segurança que não são garantidas pelas democracias mais jovens, que estão mais sujeitas a turbulências. Por outro lado, as teorias que determinavam que bastava garantir o mercado para que a democracia fosse implementada acabaram sendo refutadas pelos próprios fatos. ${ }^{56}$

A inadequação desta tese diante dos desafios da realidade colocou em evidência que Estado e mercado, ainda que estreitamente ligados, possuem funções diversas que não podem ser sobrepostas. Assim, é essencial que seja assegurado e mantido um crescimento econômico capaz de trazer uma manutenção ou melhoramento das condições de vida ${ }^{57}$ e aqui se evidencia a importância da proteção do direito de propriedade. Sendo uma das tarefas fundamentais de um Estado democrático a garantir da sua tutela efetiva.

\section{ESTADO DE DIREITO E GARANTIA CONSTITUCIONAL PROPRIEDADE}

Como anteriormente salientado, uma das tarefas principais do Estado democrático é garantir o direito de propriedade e propiciar a sua tutela efetiva. A tarefa se concretiza não apenas através do direito civil, mas, sobretudo, pelo nível de proteção constitucional conferido ao supracitado direito. Em um contexto multinacional surgem dificuldades para determinar um padrão mínimo que deve ser garantido pelas Constituições democráticas com o intuito de

\footnotetext{
${ }^{55}$ Cf. KURLANTZICK, Joshua. Democracy in retreat. The Revolt of The Middle Class and the Worldwide Decline of Representative Government. New Haven-London: Yale University Press, 2013. O livro traz casos de autoritarismo que obtiveram o apoio da classe média.

${ }^{56}$ Ibidem. p. 58 ss.

57 PRZEWORSKI, Adam; ALVAREZ, Michel; JCHIEBUB, Jose Antonio et al. Democracy and Development: Political Institutions and Well-Being in the World, 1950-1990. Cambridge: Cambridge University Press, 2000, p. 11: "deaths of democracies follow a clear pattern: they are more likely when a country experiences an economic crisis, and in most cases they are accompanied by one."
} 
assegurar o pleno exercício das liberdades individuais juntamente com o desenvolvimento econômico.

Aqui se põe a relevante questão acerca do significado da garantia constitucional da propriedade privada. Tal garantia significa que uma posição jurídica de direito privado conferida ao particular é também garantida pelo direito público e pode ser exigida diante do Estado, preservando o indivíduo da arbitrariedade. Em outras palavras: o direito de propriedade pode ser concebido como um direito subjetivo exigível entre os particulares e também como um direito subjetivo público de defesa em face do Estado e especificamente nesta última perspectiva deve ser compreendida a garantia constitucional da propriedade.

Neste sentido, "a posição juridica de direito privado é um mero pressuposto da garantia constitucional da propriedade" 58 e com ela não se confunde, pois, a uma posição jurídica de direito privado é associado um direito de defesa ou de garantia desta posição, que possui a eficácia de excluir terceiros do seu âmbito de atuação, além de vincular o poder público. Tratase inicialmente de direitos que estruturam as relações entre os privados e que apenas posteriormente serão oponíveis ao Estado; ao mesmo tempo, este último tem o dever de assegurar um espaço de liberdade aos particulares, dentro do qual este possam exercer a autonomia privada..$^{59}$

Considerando que a proteção do indivíduo é um dos pilares que alicerça a ideia de Estado de Direito ${ }^{60}$-que associado a sua vertente democrática, impõe o reconhecimento do primado império da lei, da segurança jurídica e dos direitos fundamentais - a existência de regras claras de atribuição da propriedade e de solução de conflitos entre proprietários e não proprietários é fundamental para o bom funcionamento das instituições. Demonstra ainda como as regras jurídicas podem impactar a vida dos indivíduos na promoção de um ambiente no qual as garantias institucionais sejam mantidas e as instituições jurídicas preservadas.

Outra questão importante refere-se ao alcance da supracitada garantia e do seu alcance, o que impõe uma reflexão sobre o conteúdo das posições jurídicas patrimoniais constitucionalmente protegidas. O tema coliga-se à justificação da propriedade nas democracias constitucionais e remete às garantias institucionais que podem assegurar ao

\footnotetext{
${ }^{58}$ BRITO, Miguel Nogueira de. Entre o privilégio e a liberdade. Op. cit. p. 45.

59 Sobre a ligação intrínseca entre o conceito de autonomia privada e o de propriedade, consultar: PRATA, Ana. A tutela constitucional da autonomia privada. Coimbra: Almedina, 2001, p. 07.

${ }^{60} \mathrm{Cf}$. Reporte sobre el Estado de Derecho adoptado por la Comisión de Venecia en su 86a sesión plenaria (Venecia, 25-26 de marzo de 2011). p 03. Disponível em: <http://www.venice.coe.int/webforms/documents/default.aspx?pdffile=CDL-AD(2011)003rev-spa >. Acesso em: 03 abr. 2017.
} 
indivíduo uma posição de liberdade diante dos poderes públicos. A questão não pode ser enfrentada sem dificuldades, pois a compreensão do direito de propriedade como um direito fundamental de primeira geração não é partilhada por todas as Constituições democráticas contemporâneas, ${ }^{61}$ contudo, estas, de um modo geral, apresentam dois elementos comuns que são garantidos ao titular: o aproveitamento privado e o poder de disposição. ${ }^{62}$

Adicionalmente, a compreensão da propriedade como um direito fundamental permite a reflexão sobre o papel por ela desempenhado como fator de estabilização e/ou concretização de uma democracia. Tendo em vista a dificuldade de uniformizar o próprio entendimento acerca do conceito de Estado de Direito, têm-se efetuado tentativas de estabelecer alguns padrões comuns que possam avaliar o nível de efetividade de um regime democrático e das suas garantias institucionais. Dentre elas destacam-se as iniciativas promovidas pela Comissão de Veneza para a democracia através do Direito, doravante Comissão de Veneza. ${ }^{63}$

\section{A Comissão de Veneza para a democracia através do Direito: em busca de padrões mínimos}

Com sede em Estrasburgo, a Comissão de Veneza é um órgão consultivo do Conselho da Europa sobre questões constitucionais, instituído em 1990 com o objetivo de promover o aperfeiçoamento das instituições democráticas contemporâneas. Desde a sua instituição, tornou-se um órgão de referência internacional e tem emitido uma série de pareceres e recomendações, inseridos em três eixos temáticos:

a. Instituições democráticas e direitos fundamentais;

b. Eleições, referendum e partidos políticos ;

\footnotetext{
${ }^{61}$ Algumas Constituições europeias preveem a propriedade como um direito ou relação econômica e não como um direito fundamental. É o caso da Constituição italiana. No ordenamento italiano tal direito não é considerado fundamental: a Constituição o prevê no art. 42 que trata das relações econômico-sociais, e determina que ao mesmo seja dado função social. A previsão da cláusula da função social decorre da necessidade de conciliação entre as diversas tendências que contribuíram para a redação do texto constitucional italiano.

${ }^{62}$ Cf. BRITO, Miguel Nogueira de. Entre o privilégio e a liberdade. Op. cit. p. 47.

${ }^{63} \mathrm{Na}$ segunda parte do presente trabalho, optou-se pela exame dos padrões surgidos na tradição continental, inobstante existam importantes iniciativas que não se enquadram em tal contexto. Frise-se que o confronto entre as duas tradições apresenta utilidade para a construção de um consenso mínimo acerca dos valores que devem protegidos pelo Estado que atua sob o império da lei e do respeito aos direitos fundamentais Sobre o tema, é interessante consultar: KAPSTEIN, Ethan B.; CONVERSE, Nathan. The Fate of Young Democracies. New York: Cambridge University Press, 2008; KAPSTEIN, Ethan B; CONVERSE, Nathan. Why democracies fail. In: Journal of Democracy, vol. 19, $\mathrm{n}^{\circ}$. 4, October 2008, pp. $57-$ 68. Disponível em: <http://cddrl.fsi.stanford.edu/sites/default/files/19.4.kapstein.pdf>. Acesso em: 03 abr. 2017.
} 
C. Justiça constitucional.

Não é despiciendo mencionar que Conselho da Europa é a principal organização em matéria de cooperação jurídica do continente europeu ${ }^{64}$, criado após o fim na Segunda Guerra, em 1949, ${ }^{65}$ com o intuito de promover a defesa dos direitos humanos e articular acordos destinados a harmonizar as práticas sociais e jurídicas na Europa. O Conselho tem como pilares o Estado de Direito, a democracia e os direitos humanos. ${ }^{66}$ Em sua estrutura, além de Comissão de Veneza encontra-se ainda a Corte Europeia de Direitos do Homem (Corte EDH), a quem compete zelar pelo cumprimento da Convenção Europeia dos Direitos Humanos (CEDH). ${ }^{67}$ Todos os membros do Conselho da Europa assinaram a citada Convenção, ${ }^{68}$ fruto de orientações teóricas constantes ao longo dos anos e dos debates políticos, econômicos e jurídicos promovidos para gerar estabilidade no continente.

Por seu turno, a Comissão de Veneza parte da premissa de que a regulação jurídica pode estimular o desenvolvimento das instituições democráticas e busca estabelecer padrões de respeito ao Estado de Direito a serem adotados pelas Constituições de seus membros, em conformidade com o patrimônio constitucional europeu. Com tal objetivo, organiza estudos transnacionais e promove a realização de seminários e colóquios relativos à matéria

${ }^{64}$ Composto por 47 membros ativos, (incluídos os 28 dos que são membros da União Europeia) e 8 observadores ( 5 no conselho, 3 na assembleia) atualmente desempenha um importante papel na busca de soluções comuns para as questões jurídicas e legislativas que tenham por base o respeito pela democracia, pelos direitos do homem e pelo Estado de direito. Cf. Conselho da Europa. Gabinete de Documentação e Direito Comparado. Disponível em: <http://www.gddc.pt/cooperacao/materia-civilcomercial/conselho-europa.html>. Acesso em: 03 abr. 2017.

65 O Estatuto da Conselho da Europa foi adotado em Londres, no dia 5 de maio de 1949 e entrou em vigor na ordem internacional no dia 3 de agosto de 1949.

${ }^{66}$ Cf. Estatuto do Conselho da Europa: Preâmbulo: "Reafirmando a sua adesão aos valores espirituais e morais, que são o património comum dos seus povos e que estão na origem dos princípios da liberdade individual, da liberdade política e do primado do Direito, sobre os quais se funda qualquer verdadeira democracia; Convencidos de que, a fim de salvaguardar e de fazer progressivamente triunfar este ideal e favorecer o progresso social e económico, se impõe uma união mais estreita entre os países europeus animados dos mesmos sentimentos; Considerando a necessidade de criar uma organização agrupando os Estados europeus numa associação mais estreita, com vista a responder a este imperativo e às aspirações manifestadas pelos seus povos; decidiram, em consequência, constituir um Conselho da Europa, compreendendo um Comité de representantes dos Governos e uma Assembleia Consultiva, e para esse fim adoptaram o presente Estatuto" Art. $3^{\circ}$ : "Todos os Membros do Conselho da Europa reconhecem o princípio do primado do Direito e o princípio em virtude do qual qualquer pessoa colocada sob a sua jurisdição deve gozar dos direitos do homem e das liberdades fundamentais, comprometendose a colaborar sincera e activamente na prossecução do objectivo definido no capítulo I". (Disponível em: $<\quad$ www.gddc.pt/direitos-humanos/textos-internacionais-dh/tidhregionais/conv-tratados-05-05-949-ets1.html >. Acesso em: 04 mar. 2017).

${ }^{67}$ A Convenção Europeia de Direitos Humanos é o principal tratado do Conselho da Europa. Foi instituída em Roma em 4 de novembro de 1950 e entrou em vigor em 3 de setembro de 1953.

68 Cabe frisar que a adesão da União Europeia à Convenção, que se tornou obrigatória com o Tratado de Lisboa, constitui o maior passo para o desenvolvimento dos direitos humanos na Europa. 
constitucional, que têm contribuído para o aperfeiçoamento das instituições europeias e influenciado outros países não europeus na definição de normas baseadas em um padrão de qualidade democrático. ${ }^{69}$

Em 2013, com vistas a ampliar os debates para além das fronteiras europeias, foi criada Subcomissão de Veneza para a América Latina para examinar os problemas relativos ao desenvolvimento e reforço das instituições democráticas na região. ${ }^{70}$ No mesmo ano, foram organizados dois grandes eventos internacionais para demarcar o início dos diálogos: a Conferência de Arequipa, no Peru, sobre o acesso individual à justiça constitucional, (maio), e o Seminário Internacional sobre a implementação dos tratados de direitos humanos nos ordenamentos nacionais, na Cidade do México (outubro). Estes projetos permitiram o compartilhamento experiências vivenciadas pelos diversos ordenamentos jurídicos e promoveram a aproximação dos sistemas jurídicos dos Estados participantes.

O evento realizado no Peru contou com as presenças das Cortes Constitucionais da Argentina, Brasil, Bolívia, Chile, Colômbia, República Dominicana, Equador, Guatemala, Paraguai, Peru, Uruguai e Venezuela. ${ }^{71}$ Como desdobramento dos debates, em maio de 2014 ocorreu no Brasil, em Ouro Preto a "Conferência sobre a proteção dos direitos econômicos e sociais em tempos de crise econômica" na qual os componentes ressaltaram a tentativa de harmonização entre os diferentes pontos de vista de cada jurisdição, tendo em comum o

69 Cf. artigos $1^{\circ}$. e $2^{\circ}$. da Resolução (2002) 3 que implementa modificações no Estatuto da Comissão de Veneza para a democracia através do Direito, adotado na 784a. Reunião do Comitê de Ministros, realizada em 21 fevereiro de 2002. Disponível em: Disponível em: < http://www.venice.coe.int/WebForms/pages/?p=01_01_Statute>. Acesso em: 04 mar. 2017.

1. The European Commission for Democracy through Law shall be an independent consultative body which co-operates with the member states of the Council of Europe, as well as with interested nonmember states and interested international organizations and bodies. Its own specific field of action shall be the guarantees offered by law in the service of democracy. It shall fulfill the following objectives: strengthening the understanding of the legal systems of the participating states, notably with a view to bringing these systems closer; promoting the rule of law and democracy; examining the problems raised by the working of democratic institutions and their reinforcement and development. 2. The Commission shall give priority to work concerning: a. the constitutional, legislative and administrative principles and techniques which serve the efficiency of democratic institutions and their strengthening, as well as the principle of the rule of law; b. fundamental rights and freedoms, notably those that involve the participation of citizens in public life; c. the contribution of local and regional self-government to the enhancement of democracy.

${ }^{70}$ Cabe notar que o Estado brasileiro consta como membro da Sub-Comissão, sendo representado pela Ministra Carmen Lucia Antunes Rocha, presidente do Supremo Tribunal Federal. Disponível em: < http://www.stf.jus.br/portal/cms/verNoticiaDetalhe.asp?idConteudo=105809>. Acesso em: 04 mar. 2017.

71 Council of Europe. Latin America - Recent Cooperation. Disponível em: < http://www.venice.coe.int/WebForms/pages/?p=03_Latin_America\&lang=EN >. Acesso em: 04 mar. 2017. 
reconhecimento da importância o reconhecimento que a democracia pode ser promovida e aperfeiçoada através do direito. ${ }^{72}$

Uma das principais reflexões sobre a promoção de um consenso mínimo acerca dos elementos componentes da noção de Estado de Direito encontra-se presente no estudo $n^{\circ}$. 512/09, posteriormente adotado como um Relatório da Comissão de Veneza em sua 86 a sessão plenária, ocorrida em março de $2011 .{ }^{73}$ A pesquisa foi solicitada basicamente por dois motivos:

1. A necessidade de uniformizar o conceito para garantir os padrões mínimos de proteção que dele decorrem;

2. A vagueza semântica da Resolução n. 1594/07, intitulada "O princípio do Estado de Direito", expedida pela própria Comissão. ${ }^{74}$

Inicialmente, aponta que a noção de Estado de Direito, apesar de prevista como um dos pilares do Conselho da Europa, não possui uma definição concreta; resta apenas como uma espécie de enunciação genérica. De outra feita, salienta que a noção de Estado de Direito tem sido cada vez mais incluída em documentos internacionais, o que demonstra a necessidade de um consenso mínimo sobre os elementos a serem protegidos num contexto internacional.

Para solucionar o problema, o estudo buscou uma definição que conciliasse as diversas tradições constitucionais europeias - "Estado de Direito" e de "Rechtsstaat"75 - e gerasse repercussões práticas no aperfeiçoamento das legislações nacionais. Assim, com o intuito de estabelecer uma definição consensual e a identificação dos elementos essenciais do Estado de Estado de Direito comuns ao patrimônio constitucional europeu, optou-se pelo exame das fontes europeias existentes: o Estatuto do Conselho da Europa e a Convenção Europeia de Direitos do Homem.

O preâmbulo do Estatuto da salienta a existência de um patrimônio comum europeu, composto por valores morais e espirituais e por tradições políticas que primam pelo respeito à

\footnotetext{
72 Seminário Internacional sobre a Proteção dos Direitos Econômicos e Sociais em tempos de crise econômica e o papel dos juízes. Conclusões. Disponível em: $<$ http://www.stf.jus.br/arquivo/cms/noticiaNoticiaStf/anexo/CartaOuroPreto.pdf>. Acesso em: 04 mar. 2017

${ }^{73}$ Cf. Reporte sobre el Estado de Derecho adoptado por la Comisión de Venecia en su 86a sesión plenaria (Venecia, 25-26 de marzo de 2011. p . 5. Disponível em: $<h t t p: / / w w w . v e n i c e . c o e . i n t / w e b f o r m s / d o c u m e n t s / ? p d f=C D L-A D>$. Acesso em: 04 mar. 2017. 0 documento aponta as diferenças entre os dois conceitos, aduzindo que o conceito de Rechtsstaat se refere essencialmente à natureza do Estado e surgiu das Constituições escritas, enquanto o Estado de Direito surgiu dos tribunais.

${ }^{74}$ Cf. Reporte sobre el Estado de Derecho adoptado por la Comisión de Venecia en su 86a sesión plenaria (Venecia, 25-26 de marzo de 2011. Op. cit. p.18.

${ }^{75}$ Idem. p. 3 sobre el Estado de Derecho adoptado por la Comisión de Venecia en su 86a sesión plenaria (Venecia, 25-26 de marzo de 2011. Op. cit. p. 3
} 
liberdade individual e ao direito. Menciona ainda a "rule of Law" como um dos três princípios, que juntamente com liberdade individual e liberdade política "formam a base de todas as verdadeiras democracias". ${ }^{76}$ Na mesma linha, a Convenção Europeia de Direitos do Homem aduz ao patrimônio compartilhado pelos governos europeus, baseado em tradições políticas que reconhecem o primado do direito e o valor da liberdade. ${ }^{77}$ Inobstante tais previsões, o relatório aponta que tais disposições legislativas são excessivamente genéricas e não trazem padrões concretos de proteção.

Diante da necessidade de concretização da noção, os padrões propostos pelo relatório foram baseados nas decisões da interpretação dada à Convenção Europeia dos Direitos do Homem pela jurisprudência da $\mathrm{CEDH}^{78}$ Tais padrões foram sistematizados pelo estudo $\mathrm{n}^{0}$. 512/09, nos seguintes termos:

1. Legalidade;

2. Segurança jurídica;

3. Proibição da arbitrariedade;

4. Acesso à justiça diante de tribunais independentes e imparciais;

5. Respeito aos direitos humanos;

6. Não discriminação e igualdade perante a lei. ${ }^{79}$

\footnotetext{
${ }^{76} \mathrm{Cf}$. nota 59.

77 Convenção para a Proteção dos Direitos do Homem e das Liberdades Fundamentais. Roma, 4.11.1950. Disponivel em: < http://www.echr.coe.int/Documents/Convention_POR.pdf>. Acesso em: 04 mar. 2017. Preâmbulo:"Considerando que a finalidade do Conselho da Europa é realizar uma união mais estreita entre os seus Membros e que um dos meios de alcançar esta finalidade é a protecção e o desenvolvimento dos direitos do homem e das liberdades fundamentais, Reafirmando o seu profundo apego a estas liberdades fundamentais, que constituem as verdadeiras bases da justiça e da paz no mundo e cuja preservação repousa essencialmente, por um lado, num regime político verdadeiramente democrático e, por outro, numa concepção comum e no comum respeito dos direitos do homem, Decididos, enquanto Governos de Estados Europeus animados no mesmo espírito, possuindo um património comum de ideais e tradições políticas, de respeito pela liberdade e pelo primado do direito, a tomar as primeiras providências apropriadas para assegurar a garantia colectiva de certo número de direitos enunciados na Declaração Universal, convencionaram o seguinte (...). Disponível em: < http://www.echr.coe.int/Documents/Convention_POR.pdf>. Acesso em: 04 mar. 2017.

78 O estudo salienta que o exame das decisões permite o acesso a relevantes informações de ordem prática que contribuem a observação de elementos comuns de proteção para a concretização do conceito de Estado de Direito e são úteis ainda para verificar alguns elementos reconhecidos pelos Estados europeus nos seus próprios textos constitucionais e nas suas jurisprudências constitucionais. Cf. Reporte sobre el Estado de Derecho adoptado por la Comisión de Venecia en su 86a sesión plenaria. Venecia, 25-26 de marzo de 2011. Op. cit. p.8

79 Idem. p. 13.
} 
Para cada um dos elementos apontados foram estabelecidos questionamentos, cuja resposta, positiva ou negativa permitiam verificar o grau e a forma de cumprimento de cada um dos preceitos nos diversos países.

Com base neste primeiro documento, em 02 de março de 2012, a Comissão de Veneza, em cooperação com o Comitê de Ministros do Conselho da Europa, organizou em Londres a conferência intitulada "The Rule of Law as a practical concept" ${ }^{80}$ Como conclusão, salientou-se que a Comissão deveria preparar um documento que contivesse uma maior especificação dos padrões até então desenvolvidos, uma espécie de "checklist" dos elementos do Estado de Direito que contivesse as discussões e propostas surgidas no evento.

Em resposta a tal sugestão, a Comissão nomeou um novo grupo de especialistas para realizar o Estudo $n^{\circ}$. 711/2013, que foi apresentado na sessão de 29 de fevereiro de $2016^{81}$ e adotado na $106^{a}$ Sessão Plenária, realizada entre os dias 11 e 12 de março do mesmo ano. ${ }^{82} \mathrm{O}$ documento, mais detalhado que o anterior, divide-se em três partes:

i. Introdução;

ii. A definição dos padrões de comparação;

iii. Fontes selecionadas.

A parte introdutória explana os objetivos do relatório e ressalta a inter-relação entre o Estado de Direito, a democracia e os direitos humanos, valores que estão na base do Conselho da Europa. Ressalta ainda que tal conexão é reconhecida pela jurisprudência da CEDH em diversas expressões utilizadas em seus julgados, dentre elas, "democratic society subscribing to the Rule of Law", "democratic society based on the Rule of Law" e "Rule of Law in a democratic society". ${ }^{83}$

A segunda parte especifica os padrões do Estado de Direito contidos no relatório de 2011 legalidade, certeza jurídica, proibição da arbitrariedade, mau uso (ou abuso) do poder e

80 Conference on the rule of law as a pratical concept. Lancaster House. London, 02 march 2012. Disponível em: $\quad$ Disponível em: http://www.venice.coe.int/webforms/documents/default.aspx?pdffile=CDL(2013)016-e>. Acesso em: 04 mar. 2017.:

${ }^{81}$ European Commission for Democracy Through Law (Venice Commission). Draft checklist on the rule of law. Disponível em: <http://www.venice.coe.int/webforms/documents/?pdf=CDL(2016)006-e>. Acesso: 06 mar. 2017

82 Rule of Law Checklist, adopted by the Venice Commission at its 106th Plenary Session. (Venice, 11-12 March 2016). Disponível em: <http://www.venice.coe.int/webforms/documents/?pdf=CDL-AD(2016)007e>.Acesso em: 06 mar. 2017.

83 Rule of Law Checklist, adopted by the Venice Commission at its 106th Plenary Session. (Venice, 11-12 March 2016). Op. cit. p.6. 
luta contra a corrupção, vigilância e coleta de dados; igualdade perante a lei e acesso à justiça ${ }^{84}$ A parte final versa sobre a legislação internacional que trata dos diversos aspectos da "Rule of Law", em especial as normativas da União Europeia.

Considerando que a associação entre o Estado de Direito e democracia foi anteriormente salientada pelos pronunciamentos da Corte e também a Comissão de Veneza, justifica-se a aproximação entre propriedade e democracia exposta na primeira parte do presente texto.

Considerando ainda que a legalidade e a certeza jurídica são padrões do estabelecidos pela Comissão para a verificação do cumprimento dos ditames que decorrem da noção de Estado de Direito, analisar-se-á como tais vetores se expressam nos regimes proprietários europeus. Com tal intuito, nas próximas páginas pretende-se examinar especificamente alguns casos concretos que permitem os delineamentos da tutela concedida à propriedade pelas democracias europeia em geral, com base nos pareceres da Comissão de Veneza e nas decisões da Corte Europeia de Direitos Humanos.

\section{A Corte Europeia de Direitos Humanos e o controle da garantia constitucional da propriedade nas democracias europeias ${ }^{85}$}

O reconhecimento da propriedade como um direito fundamental pela Convenção Europeia dos Direitos do Homem tem estimulado a reflexão não apenas sobre a natureza deste direito, mas também sobre o nível de proteção que deve ser ao mesmo concedido.

Igualmente, a Carta dos Direitos Fundamentais da União Européia ${ }^{86}$ consagra o direito de propriedade como direito fundamental do indivíduo e prevê que ninguém poderá ser privado dos seus bens, a não em virtude do interesse público, nos casos previstos em lei e

\footnotetext{
${ }^{84}$ Idem. pp. 11-18

${ }^{85}$ Por "direito europeu" ou "propriedade europeia" faz-se menção ao complexo de normas que emanam das seguintes fontes: "Convenção Européia para a proteção dos direitos do homem e das liberdades fundamentais", à Carta dos direitos fundamentais da União Européia, ao Tratado de Lisboa, e à jurisprudência da Corte EDU e do Tribunal de Justiça da União Europeia.

${ }^{86}$ Cabe esclarecer que a Carta de Direitos Fundamentais da União Europeia não se confunde com a Convenção Europeia de Direitos Humanos. A Carta é um documento produzido e assinado pelos membros da União Europeia, com o fito de promover a proteção comum de direitos fundamentais que assinalam valores comuns partilhados pelos membros da UE. A Convenção Europeia de Direitos Humanos é o principal tratado do Conselho da Europa, cuja guarda compete Corte Europeia de Direitos do Homem, órgão do Conselho da Europa, a quem compete zelar pelo cumprimento da Convenção e julgar os casos em que há alegação de violação da mesma. A Corte não se confunde com o Tribunal de Justiça da União Europeia, a quem compete velar pela cumprimento e uniformização do direito europeu.
} 
garantida uma justa indenização em tempo útil. ${ }^{87}$ Seu preâmbulo ${ }^{88}$ prevê a aplicação subsidiária dos direitos e das obrigações internacionais que decorrem da Convenção Europeia de Direitos do Humanos do Homem, bem como da jurisprudência da Corte EDH. ${ }^{89}$

A temática está diretamente relacionada à associação entre propriedade e Estado de Direito, conforme salientado na primeira parte do corrente estudo. Como é sabido, o Estado de Direito se ocupa do exercício do poder na relação entre o indivíduo e o Estado.

A sistematização efetiva dos elementos sobre os quais há uma certa uniformidade de opiniões auxilia no estabelecimento de padrões de tutela das garantias individuais, dentre os quais inclui-se a garantia constitucional da propriedade. Concretiza ainda o grau de respeito às instituições que deve ser assegurado nas democracias contemporâneas para que seja efetivamente implementado o "império da lei" ${ }^{90}$

${ }^{87}$ Carta dos Direitos Fundamentais da União Europeia. Art. 17: Direito de propriedade. 1. Todas as pessoas têm o direito de fruir da propriedade dos seus bens legalmente adquiridos, de os utilizar, de dispor deles e de os transmitir em vida ou por morte. Ninguém pode ser privado da sua propriedade, excepto por razões de utilidade pública, nos casos e condições previstos por lei e mediante justa indemnizaçao pela respectiva perda, em tempo útil. A utilização dos bens pode ser regulamentada por lei na medida do necessário ao interesse geral. 2. É protegida a propriedade intelectual. (Disponível em: http://www.europarl.europa.eu/charter/pdf/text_pt.pdf. Acesso em: 11. mar. 2017)

88 Preâmbulo da Carta de Direitos Fundamentais da União Europeia: (...) A presente Carta reafirma, no respeito pelas atribuições e competências da Comunidade e da União e na observância do princípio da subsidiariedade, os direitos que decorrem, nomeadamente, das tradições constitucionais e das obrigações internacionais comuns aos Estados-Membros, do Tratado da União Europeia e dos Tratados comunitários, da Convenção europeia para a proteção dos direitos do Homem e das liberdades fundamentais, das Cartas Sociais aprovadas pela Comunidade e pelo Conselho da Europa, bem como da jurisprudência do Tribunal de Justiça das Comunidades Europeias e do Tribunal Europeu dos Direitos do Homem. Disponível em: < http://www.europarl.europa.eu/charter/pdf/text_pt.pdf >. Acesso em: 06 mar. 2017.

${ }^{89}$ O Tratado de Roma, que institui a União Europeia (UE), prevê em seu artigo 345 o princípio da neutralidade, o qual determina que os tratados dela decorrentes não devem prejudicar o regime de propriedade previsto nos Estados-membros. Contudo, cabe ao legislador europeu regulamentar matérias de sua competência, dentre elas, o comércio, a agricultura, os bens culturais e o meio-ambiente, questões que, ainda que de modo indireto, interferem na disciplina jurídica da propriedade. O Tribunal de Justiça da UE tem interpretado de modo dinâmico o princípio da neutralidade, o que significa dizer que este, apesar de não interferir nas escolhas dos regimes proprietários pelos Estados- membros, deve verificar a sua compatibilidade com o processo de integração.

${ }^{90}$ Cabe frisar que historicamente o Estado de Direito desenvolveu-se como forma de restringir o poder do Estado e os direitos humanos eram vistos como direitos contra as intromissões dos detentores do poder (direitos negativos). Atualmente, a percepção dos direitos humanos tem mudado, tanto na legislação dos Estados como nas legislações internacionais, as quais tem atribuído obrigações positivas aos Estados, no sentido de garantir a efetividade do sistema de proteção aos direitos fundamentais. Sobre o tema, consultar: CANÇADO TRINDADE, Antônio Augusto. Dilemas e desafios da Proteção Internacional dos Direitos Humanos no limiar do século XXI. In: Revista Brasileira de Política Internacional. vol.40, n. 1, 1997, pp: 167-177 
Neste particular, a CEDH entende que o conceito de Estado de Direito perpassa todos os artigos previstos na Convenção Europeia dos Direitos do Homem. ${ }^{91}$ Defende também que a democracia é inerente ao próprio conceito de Estado de Direito ${ }^{92}$ o que significa dizer que, a contrario sensu, qualquer violação da Convenção implica necessariamente uma afronta ao Estado de Direito e à democracia. Cabe ressaltar que a admissibilidade de pleito individual contra o Estado num Tribunal Internacional, prevista pela CEDH, é um importante mecanismo de defesa do indivíduo e permite um maior acesso à justiça e de participação democrática. ${ }^{93}$

A Corte atribui especial importância à propriedade enquanto expressão da liberdade humana e considera que a sua noção está ligada a uma economia de mercado, na qual a tutela da propriedade deve garantir a plena concorrência baseada na livre iniciativa. Por isso, considera que a ausência de regras claras sobre o regime de propriedade interfere na segurança jurídica e na proteção do indivíduo contra a arbitrariedade estatal e viola o artigo $1^{\circ}$. do Protocolo adicional à Convenção Europeia de Direito Humanos ${ }^{94}$

Nas suas decisões pode-se vislumbrar a proteção dada ao núcleo essencial da propriedade. Dentro de tal perspectiva, os limites impostos pelo interesse público ou pela função social devem ser pontuais e restritos. Além disso, a expropriação da propriedade privada deve estar justificada pelo ordenamento jurídico de cada um dos países, que deve ainda garantir uma indenização compensatória e razoável ao proprietário, bem como a proporcionalidade da medida.

${ }^{91}$ Cf. decisão da Corte EDH no caso Sttaford v. United Kingdon, de 28 de maio de 2002, parágrafo 63. Disponível em: <http://swarb.co.uk/stafford-v-the-united-kingdom-echr-28-may-2002/>. Acesso em: 05 abr. 2017.

92 Idem.

93 "The Rule of Law is linked not only to human rights but also to democracy, i.e. to the third basic value of the Council of Europe. Democracy relates to the involvement of the people in the decision-making process in a society; human rights seek to protect individuals from arbitrary and excessive interferences with their freedoms and liberties and to secure human dignity; the Rule of Law focuses on limiting and independently reviewing the exercise of public powers. The Rule of Law promotes democracy by establishing accountability of those wielding public power and by safeguarding human rights, which protect minorities against arbitrary majority rules". Cf. Rule of Law Checklist, adopted by the Venice Commission at its 106th Plenary Session. (Venice, 11-12 March 2016). Op. cit. p. 9.

94 Artigo $1^{\circ}$. do Protocolo adicional à Convenção Europeia de Direitos do Homem: "Protecção da propriedade Qualquer pessoa singular ou colectiva tem direito ao respeito dos seus bens. Ninguém pode ser privado do que é sua propriedade a não ser por utilidade pública e nas condições previstas pela lei e pelos princípios gerais do direito internacional. As condições precedentes entendem - se sem prejuízo do direito que os Estados possuem de pôr em vigor as leis que julguem necessárias para a regulamentação do uso dos bens, de acordo com o interesse geral, ou para assegurar o pagamento de impostos ou outras contribuições ou de multa”. Disponível em: http://www.echr.coe.int/Documents/Convention_POR.pdf>. Acesso em: 05 abr. 2017. 
A Corte tem dado uma interpretação garantista a estas restrições, no sentido de promover aplicação do princípio da máxima tutela dos direitos fundamentais na legislação dos países signatários da Convenção Europeia de Direitos Humanos. Tomando por base o artigo 46 da citada Convenção, que prevê a vinculatividade de suas decisões, criou a figura do déficit estrutural da disciplina dos direitos humanos, que ocorre quando um Estado-parte da Convenção traz na sua legislação ordinária uma previsão deficitária e pouco garantista de um direito fundamental. ${ }^{95}$

Igualmente, a associação entre propriedade, Estado de Direito e democracia pode ainda ser demonstrada nos pareceres emitidos pela Comissão de Veneza ${ }^{96}$. Cite-se como exemplo a sua atuação em 2016 como "amicus curiae", diante da Corte Constituc da Albânia. No exercício de suas funções, a Comissão elaborou um relatório, aprovado na $108^{a}$. Sessão Plenária (Veneza, 14 e 15 de outubro de 2016), no qual analisou os aspectos legais relativos à restituição das propriedades confiscadas pelo regime comunista anterior. ${ }^{97}$

\footnotetext{
95 É o caso da Itália, cuja Constituição prevê não só a propriedade como direito econômico, mas também atribui uma função social ao mesmo, o que tem legitimado as intervenções do Estado na propriedade a pretexto do interesse geral. A Constituição italiana, baseada no valor social do trabalho e na forte intervenção do Estado na economia, em especial no que tange à propriedade agrária, classifica o direito de propriedade como um direito econômico, que deve ser submetido a considerações de utilidade social. O artigo 42 não prevê a propriedade como direito fundamental da pessoa, de modo a delimitar uma esfera de não intervenção do Estado, mas como direito de participação na organização e no desenvolvimento da vida econômica. O proprietário é protegido dentro deste papel participativo, reservando à "lei a determinação dos modos de aquisição, gozo e limites, de modo a assegurar a sua função social". A ratio da tutela constitucional não é a proteção da propriedade enquanto expressão da liberdade individual, mas da sua funcionalidade dentro do sistema econômico. Sob a fórmula da função social da propriedade, não é assegurado um conteúdo mínimo a tal direito, que pode ser livremente conformado pela lei, a quem cabe fixar-lhe o próprio conteúdo.Por tal motivo, o país foi condenado por déficit estrutural das disciplina da propriedade em 2007, o que ocasionou a mudança de orientação da Corte Constitucional quanto à ocupação aquisitiva e a expropriação. A partir de dois casos emblemáticos, a Corte Constitucional italiana promoveu a adequação da sua jurisprudência, por entender que a adesão do país à Convenção teria promovido a inserção de um novo tipo de fonte no ordenamento nacional: as chamadas normas interpostas, isto é, normas da convenção tais como interpretadas pela Corte em suas decisões definitivas como instrumento de proteção dos direitos humanos. Sobre o tema, ver: CONTI, Ricardo. Diritto di proprietà e CEDU. Itinerari giurisprudenziali europei. Viaggio fra Carte e Corti alla ricerca di un nuovo statuto proprietario. Brugini: Exeo Edizioni, 2012; MAGRI, Geo. Quale futuro per la funzione sociale della proprietà? Abbandonare Weimar per tornare a Locke? BOCCONI LEGAL PAPERS, 2013. Disponível em: < http://works.bepress.com/bocconi_legal_papers/40>. Acesso em: 05 abr. 2017.

96 Tais documentos fornecem um mínimo denominador comum no que se refere à tutela da propriedade no Estado de Direito. Cabe ressaltar que o controle da implementação da Convenção cabe à Corte EDH, que tem a tarefa verificar a conformidade das normas jurídicas expedidas com patrimônio comum europeu expresso na referida Convenção. Tal conexão apresenta grande relevância porque os padrões buscados pela Comissão de Veneza para a democracia através do Direito baseiam-se nas cartas internacionais de direitos, em especial da Convenção Europeia de Direitos e Humanos

97 Opinion $n^{\circ}$. 861/ 2016. Amicus curiae brief for the constitutional Court on the restitution. Adopted by the Venice Commission at its 108 th Plenary Session. Venice, 14-15 October 2016. Disponível em:
} 
Trata-se de rico documento a ser analisado, no qual constam inúmeras linhas gerais de tutela da propriedade e da proteção que deve ser dada aos proprietários pela "rule of law". O ponto inicial da controvérsia foi o questionamento da constitucionalidade da lei $n^{\circ}$. 133/2015, ${ }^{98}$ que regula o tratamento da propriedade e a finalização do processo de compensação das propriedades propriedade expropriadas durante o regime comunista, diante Corte Constitucional albanesa.

Os requerentes, além de alegarem que a mencionada lei violava a Constituição do país, aduziu também a sua incompatibilidade com o artigo $1^{\circ}$. do Protocolo n. 1 da Convenção Europeia de Direitos Humanos e com a jurisprudência da Corte EDH, por violação aos princípios da segurança jurídica, da igualdade formal e do tratamento não discriminatório. Sustentou-se que a mencionada lei traria uma grave afronta à segurança jurídica porque, com o intuito de resolver o problema crônico da não efetividade das sentenças proferidas sobre a restituição e a compensação pelo confisco de propriedades privadas durante o regime anterior, a lei trouxe novos critérios para a fixação de indenização, o que na prática equivaleria à reavaliação de decisões judiciais definitivas que não foram executadas.

Aduziram ainda que a lei violaria o princípio da igualdade e a vedação ao tratamento discriminatório porque o sistema determina uma reavaliação de decisões administrativas e judiciais com caráter definitivo e não garante efetividade, clareza e previsibilidade aos cidadãos. Por fim, alegaram a violação da proteção ao direito de propriedade, uma vez que as soluções trazidas não promovem uma avaliação real da propriedade na Albânia, por ignorar os processos administrativos e as decisões judiciais definitivas sobre a compensação da propriedade.

A fim de aclarar a dúvida, em 07 de julho de 2016, o presidente da Corte Constitucional da Albânia, Bashkim Dedja, solicitou à Comissão de Veneza um parecer sobre o assunto, no qual explicou brevemente a situação jurídica da propriedade no país e ao mesmo tempo elaborou quatro perguntas a serem respondidas pelos especialistas, conforme segue: ${ }^{99}$

http://www.venice.coe.int/webforms/documents/default.aspx?pdffile=CDL-AD(2016)023-e. Acesso: 06 mar 2017.

98 Law $n^{\circ}$. 133/2015 on the treatment of property and finalization of the process of compensation of property.

Disponível em: < http://www.venice.coe.int/webforms/documents/?pdf=CDL-REF(2016)049-e>. Acesso em: 28 mar. 2017.

${ }^{99}$ Opinion $n^{\circ}$. 861/2016. Amicus curiae brief for the constitutional Court on the restitution. Adopted by the Venice Commission at its 108 th Plenary Session. Venice, 14-15 October 2016. p. 02. Disponível em: http://www.venice.coe.int/webforms/documents/default.aspx?pdffile=CDL-AD(2016)023-e. Acesso: 06 mar 2017. 
1. A lei $n^{\circ}$. 133/2015 viola direitos adquiridos e expectativas legítimas garantidas pela Constituição albanesa e pelo artigo $1^{\circ}$. do Protocolo 1 da Convenção Europeia de Direitos do Homem?

2. As disposições da lei que determinam que as decisões finais não liquidadas ou executadas sejam reavaliadas segundo novos critérios estão em conformidade com a Convenção Europeia (CEDH) e com as decisões da Corte EDH?

3. A nova fórmula de compensação prevista é justa, real e efetiva?

4. A fórmula prevista na lei resolve de modo efetivo, transparente e previsível a problemática da indenização compensatória aos proprietários que tiveram seus bens expropriados pelo regime comunista?

Os pesquisadores nomeados pela Comissão de Veneza, primeiramente ressaltaram que o escopo da sua atuação como "amicus curiae" foi o de prover à Corte Constitucional albanesa um documento que permitisse o confronto da legislação interna com os padrões europeus de proteção à propriedade e aos direitos humanos de modo geral. Tal material de consulta deve ser cotejado com a Constituição albanesa e com a lei questionada, de modo a trazer subsídios que auxiliem na elaboração da decisão sobre a constitucionalidade dos dispositivos atacados.

Tendo feito tal esclarecimento prévio, o relatório principia por relatar a situação jurídica da propriedade na Albânia e ressalta que, logo após a queda do regime comunista, no início da década de noventa do século passado, houve uma sucessão de leis que disciplinavam a restituição das propriedades confiscadas e a compensação dos proprietários pelos prejuízos sofridos.

Justamente pela ausência de uma lei única e definitiva que contivesse critérios seguros para solucionar o problema, e também pela insuficiência de fundos para pagamento das indenizações, vários casos concretos foram levados à apreciação da CEDH, por alegação de desrespeito aos artigos $1^{\circ}$. do Protocolo 1 , ao artigo $6^{\circ} \cdot 100$ (direito a um processo equitativo) e ao artigo $13^{\circ}$. (direito a um recurso efetivo) ${ }^{101}$ da mencionada Convenção. A grande quantidade

\footnotetext{
${ }^{100} \mathrm{Art}$. $6^{\circ}$. Direito a um processo equitativo

1. Qualquer pessoa tem direito que a sua causa seja examinada, equitativa e publicamente, num prazo razoável por um tribunal independente e imparcial, estabelecido pela lei, o qual decidirá, quer sobre a determinação dos seus direitos e obrigações de carácter civil, quer sobre o fundamento de qualquer acusação em matéria penal dirigida contra ela. Disponível em: < http://www.echr.coe.int/Documents/Convention_POR.pdf>. Acesso em: 28. mar. 2017.

${ }^{101}$ Artigo $13^{\circ}$. Direito a um recurso efectivo.

Qualquer pessoa cujos direitos e liberdades reconhecidos na presente Convenção tiverem sido violados tem direito a recurso perante uma instância nacional, mesmo quando a violação tiver sido cometida por
} 
de recursos dos nacionais albaneses à Corte EDH redundou numa sequência de condenações do país por violação à Convenção Europeia de Direitos Humanos. ${ }^{102}$

Desde 2007, a Corte EDH considerando que "uma série de indivíduos ainda estão privados do direito de uso pacífico de suas propriedades como resultado do não cumprimento dos julgados em que reconhece o direito à indenização", constatou a natureza crônica do problema, originado por uma deficiência estrutural de tutela do direito de propriedade no ordenamento albanês. ${ }^{103}$ Tal insuficiência da tutela proprietária violaria não só a propriedade enquanto direito humano, mas também o direito de obter uma reparação razoável, igualmente previsto na Convenção Europeia dos Direitos do Homem (CEDH). ${ }^{104}$

Tendo em vista a gravidade da situação na Albânia, e considerando a natureza vinculativa das suas sentenças definitivas, a Corte EDH no julgamento do caso Manushaque Puto (2012), que passou a servir de referência para todos os outros casos que se enquadrassem nas mesmas premissas jurídicas e fáticas, recomendou que a Albânia introduzisse em seu ordenamento jurídico um mecanismo compensatório eficaz. Na pendência de tal solução interna, a Corte EDH continuaria a julgar regularmente as controvérsias e a exigir uma justa indenização para todos os requerentes. ${ }^{105}$

pessoas que actuem no exercício das suas funções oficiais. Disponível em: < http://www.echr.coe.int/Documents/Convention_POR.pdf>. Acesso em: 28. mar. 2017.

102 À época da redação do relatório, em outubro de 2016, havia cerca de 230 casos pendentes na Corte Europeia de Direitos Humanos e 15 casos sob a supervisão do Comitê de Ministros do Conselho da Europa, além de 40.000 casos pendentes no ordenamento jurídico albanês, segundo informações prestadas pelas autoridades do país. Cf. Albania. Amicus Curiae Brief for the Constitutional Court on the Restitution of property. Disponível em: http://www.venice.coe.int/webforms/documents/default.aspx?pdffile=CDL-AD(2016)023-e>. Acesso em: 28. mar. 2017.

103 Manushaque Puto and Others against Albania and Driza against Albania (and 14 similar cases) group. General measures for the execution of the judgments of the European Court. Disponível em: < https://rm.coe.int/CoERMPublicCommonSearchServices/DisplayDCTMContent?documentld=0900001680 5ab71e>. Acesso em: 28. mar. 2017.

${ }^{104}$ Artigo $41^{\circ}$. Reparação razoável. Se o Tribunal declarar que houve violação da Convenção ou dos seus protocolos e se o direito interno da Alta Parte Contratante não permitir senão imperfeitamente obviar às consequências de tal violação, o Tribunal atribuirá à parte lesada uma reparação razoável, se necessário. Disponível em: <http://www.echr.coe.int/Documents/Convention_POR.pdf>. Acesso em: 28. mar. 2017.

105 Diante da continuidade das condenações sem cumprimento, em 16/03/2015, o ministro da economia albanês manifestou-se sobre as sentenças condenatórias proferidas pela Corte EDH, em relatório no qual frisou que o cumprimento das sentenças ocasionaria um grave risco fiscal ao país, haja vista a inexistência de previsão orçamentários para tal fim. Diante disso, o caso foi encaminhado para o Comitê de Ministros do Conselho da Europa, órgão responsável por acompanhar as medidas executivas destinadas a dar cumprimento às decisões da Corte EDU. Dada a ameaça de grave risco para as finanças da Albânia, vários órgãos internacionais, dentre eles o FMI, o Banco Mundial, a Comissão Europeia e Conselho de UE pressionaram o país para que se procedesse à uma solução definitiva e permanente para o problema, 
A partir dos parâmetros estabelecidos pela Corte EDH no "leading case" Manushaque $\mathrm{x}$ Albânia, a partir de junho de 2015 o governo da Albânia adotou um plano de ação destinado a introduzir uma série de medidas no ordenamento jurídico albanês, com vistas à promoção de uma compensação efetiva aos proprietários expropriados. O plano de ação e sua implementação foram submetidos ao Comitê de Ministros do Conselho da Europa, a quem compete supervisionar a execução das sentenças da Corte. ${ }^{106}$ Dentre as medidas a serem implantadas, destaca-se a elaboração de uma lei destinada a trazer os critérios de compensação das propriedades anteriormente confiscadas, em conformidade com as exigências da Corte $\mathrm{EDH}$.

Com tal objetivo, em 05 de dezembro de 2015, é promulgada a Lei nº. 133/2015, com um novo esquema de compensações. A lei pretende abranger todos os tipos de expropriação, nacionalização e confisco por meio de qualquer ato legal que tenha gerado a expropriação por quaisquer meios injustos por parte do Estado desde 29 de novembro de 1944.

Sua Exposição de Motivos menciona que a lei foi elaborado com o intuito de proteger o direito constitucional de propriedade e garantir a sua restauração nos casos em que o proprietário tenha sido injustamente dela privado, em conformidade com o princípio da segurança jurídica e com o Estado de Direito. Garante-se ainda o direito à uma justa compensação nos casos de expropriação, levando-se também em consideração a ponderação com o interesse público. ${ }^{107}$

Porém, a nova lei foi também atacada por trazer critérios de compensação que propiciavam uma indenização de menor valor, em relação ao padrão anterior, o que foi tido como uma medida comparável à expropriação da propriedade privada e, por isso, levada à apreciação da Corte EDH. Esta nova provocação motivou a Corte Constitucional albanesa a solicitar o auxílio da Comissão de Veneza para que esta se manifestasse sobre a constitucionalidade da lei e a sua conformidade ou não com os padrões da Convenção Europeia de Direitos Humanos e das decisões da Corte EDH.

No parecer, a Comissão de Veneza promove um cotejo entre conteúdo da lei ${ }^{\circ}$. 133/2015 com o artigo $1^{\circ}$. do Protocolo 1 da CEDH. A partir do confronto concreto dos

baseada numa formula aceitável de compensação que pusesse fim as inúmeras demandas dos antigos proprietários diante da Corte EDH.

106 Cf. Council of Europe. Committee of Ministers. Disponível em: < http://www.coe.int/en/web/cm >. Acesso em: 28. mar. 2017.

107 Cf. Opinion $n^{\circ}$. 861/ 2016. Amicus curiae brief for the constitutional Court on the restitution. Adopted by the Venice Commission at its 108 th Plenary Session. Op. cit. p. 04. 
dispositivos da lei atacada com as decisões da Corte EDH, promovem um percurso argumentativo, a fim de verificar a pertinência ou não das alegações dos requerentes. Assim, a resposta segue dividida em quatro quesitos que pretendem aferir a compatibilidade ou não das restrições legais trazidas com o sistema de proteção dos direitos fundamentais do Conselho da Europa:

i. O primeiro passo é verificar se houve uma interferência real na propriedade;

ii. Configurada a interferência, deve-se passar à análise da sua legalidade;

iii. Constatada a legalidade, indaga-se sobre a legitimidade dos seus objetivos;

iv. Por fim, cabe aferir a proporcionalidade da intervenção.

A Comissão optou por não responder a cada quesito individualmente, uma vez que as indagações acabam por se misturar. A partir da leitura do artigo $1^{\circ}$. do protocolo 1 , o parecer vai respondendo aos quesitos, tomando por base a jurisprudência da Corte EDH sobre o tema. Para aferir a interferência na propriedade privada, a Corte EDH parte da expressão "direito ao respeito dos seus bens" prevista no artigo $1^{\circ}$. do Protocolo 1 da Convenção Europeia, que traz um conceito amplo de propriedade e engloba todos os direitos legalmente constituídos.

Segundo a interpretação do tribunal, o escopo da proteção da norma inclui as legítimas expectativas de obter o gozo efetivo do seu direito de propriedade, e, consequentemente, o direito a um julgamento final vinculativo no caso de ação reivindicatória. ${ }^{108}$ Quanto à lei $n^{\circ} .133 / 2015$, a Comissão entendeu que devem ser diferenciadas:

i. Os casos nos quais há decisões judiciais ou administrativas, que foram preservados pela nova lei;

ii. As situações concretas que não foram abrangidas por provimentos definitivos.

Para o primeiro rol de casos, a lei determina expressamente que as decisões judiciais ou administrativas finais não serão reexaminadas, aplicando-se os critérios previstos na lei anterior, e nisto não há interferência no direito de propriedade. Para as demais situações, como a lei traz um novo esquema de compensação que gera indenizações de menor valor, considera-se que,

${ }^{108}$ A Corte ressalta que o protocolo 1 da Convenção não cria a obrigação automática de restituição da propriedade por parte dos Estados que fizerem a transição de uma economia socialistas para uma economia de mercado antes da ratificação da Convenção. Contudo, uma vez que o Estado ratifique a convenção e promulgue legislação determinando a restituição total ou parcial da propriedade confiscada sob o regime anterior, tal legislação deve ser considerada como criadora de novos diretos de propriedade, e gere obrigações para o Estado. Cf. Opinion $n^{\circ}$. 861/ 2016. Amicus curiae brief for the constitutional Court on the restitution. Adopted by the Venice Commission at its 108 th Plenary Session. Op. cit. p. 06. 
tal situação pode ser qualificada como uma interferência na propriedade, à luz do artigo $1^{\circ}$. do Protocolo 1.

Configurada a interferência na propriedade privada, analisa-se a sua legalidade, nos termos do artigo $1^{\circ}$. do Protocolo 1 da Convenção. Neste particular, a Comissão considera que que a interferência é plenamente legal, por fundamentar-se em lei doméstica clara, precisa e por todos conhecida, inexistindo violação à Convenção. Quanto à legitimidade da interferência, diante da confusa situação legislativa na Albânia, o parecer entende que a lei n. 133/15 busca um objetivo legítimo e que está em conformidade com o interesse público: a finalização do processo de reconhecimento e compensação da propriedade.

Além disso, o artigo 11 da citada lei prevê a criação de um fundo no valor de 50 bilhões de "albanian leks" para financiar as compensações realizadas nos próximos 10 anos.

No que concerne à proporcionalidade da intervenção, o princípio refere-se à proporcionalidade entre os meios empregados e os objetivos a serem atingidos por eles; assim, as medidas de intervenção ou privação da propriedade devem ser idôneas a atingir os objetivos perseguidos. A previsão da lei $n^{\circ}$. 133/2015 traz uma nova configuração legal da propriedade que a Comissão de Veneza considera ser proporcional aos objetivos a serem alcançados.

Neste particular, o parecer alega que o fato de a nova configuração da propriedade na Albânia prever que a compensação deve ser calculada com base no valor cadastral da propriedade ao tempo da expropriação, satisfaz o requisito da proporcionalidade e da ponderação entre os interesses público e privado. A Comissão entender ser razoável a menção ao valor cadastral das propriedades ao tempo da ocorrência das expropriações, sem que seja considerada como uma extrema desproporção entre o valor cadastral da propriedade e a compensação paga aos proprietários formais.

Por fim, o relatório aponta que os elementos apontados pelo parecer são análises abstratas destinadas a auxiliar a Corte constitucional albanesa no julgamento da referida lei. Contudo, ressalta que a resposta definitiva sobre a conformidade da compensação prevista com o artigo $1^{\circ}$. do protocolo 1 dependerá do modo como será implementada pelas autoridades albanesas, a quem compete o juízo definitivo sobre a constitucionalidade da intervenção.

\section{CONCLUSÃO}

O Estado de Direito não implica apenas uma legalidade formal que assegure a regularidade e a consistência de uma ordem democrática, implica ainda a realização da justiça 
baseada no reconhecimento do valor supremo da personalidade humana, garantida por instituições que contêm com um marco legal para a sua proteção. ${ }^{109}$

A tutela da propriedade apresenta grande relevância como expressão do Estado de Direito e da democracia. Apesar da diversidade dos conceitos existentes, bem como do grau de tutela proprietária conferida pelos Estados, pode-se afirmar a existência de um núcleo mínimo comum que confere a tal direito seus atributos.

O reconhecimento desta como um direito humano tanto pela CEDH como pela Carta de Direitos Fundamentais da UE permitem a construção de algumas linhas gerais (ou padrões) para verificar o grau de tutela conferido ao direito de propriedade com base na "rule of law". A partir diretrizes ditadas pela Convenção Europeia de Direitos Humanos, concretizadas pelas decisões da Corte EDH pode-se caminhar na construção de padrões mínimos de tutela da propriedade que correspondam ao Estado de Direito. Tal é objetivo buscado pela Comissão de Veneza para a democracia através do Direito.

No que tange à tutela da propriedade, assim como para o conceito de Estado de Direito, os padrões construídos pela Comissão de Veneza podem auxiliar os Estado para que as legislações internas estejam em harmonia com o patrimônio constitucional europeu, expresso no Conselho da Europa, na CEDH e na jurisprudência da Corte EDH.

A Corte aponta que a democracia é um elemento inerente do Estado de Direito e salienta a existência de núcleo mínimo do direito de propriedade que deve ser respeitado pelos Estados. Suas decisões caminham no sentido de reconhecer que a propriedade enquanto direito fundamental deve ser reconhecido pelas Constituições democráticas, como expoentes da segurança jurídica e do respeito aos direitos fundamentais que deve permear o Estado de Direito.

O repositório de julgados da Corte EDH ilustra concretamente as boas práticas que devem permear a atuação do Estado e serve como auxílio aos mesmos na tarefa de harmonizar as legislações internas com o patrimônio constitucional europeu, no qual inclui-se a promoção de uma tutela efetiva do direito de propriedade. Tais padrões podem contribuir para o aperfeiçoamento não só das democracias europeias, mas sobretudo para as democracias da América Latina, em grande parte ainda em processo de consolidação.

${ }^{109} \mathrm{Cf}$. ODIHR and the rule of law. Disponível em: < http://www.osce.org/odihr/103448?download=true>. Acesso em: 08 abr. 2017. A Organização para a Segurança e Cooperação na Europa (OSCE) é uma organização de países do Ocidente voltada para a promoção da democracia e do liberalismo econômico na Europa. 


\section{REFERÊNCIAS}

ALBANIA. Amicus Curiae Brief for the Constitutional Court on the Restitution of property. Disponível em: < http://www.venice.coe.int/webforms/documents/default.aspx?pdffile=CDL-AD(2016)023-e>.

Acesso em: 28. mar. 2017.

Law $n^{\circ} .133 / 2015$ on the treatment of property and finalization of the process of compensation of property. Disponível em: http://www.venice.coe.int/webforms/documents/?pdf=CDL-REF(2016)049-e>. Acesso em: 28 mar. 2017.

ALCHIAN, Armen; DEMSETZ, Harold. The Property Rights Paradigm. In: The Journal of Economic History. vol. 33, no. 1, The Tasks of Economic History, mar.,1973, pp. 16-27. Disponível em: $<$ http://links.jstor.org/sici?sici=0022-

0507\%28197303\%2933\%3A1\%3C16\%3ATPRP\%3E2.0.CO\%3B2-A>. Acesso em: 03 abr. 2017.

BARRO, Robert G. Democracy and growth. In: Journal of Economic Growth. n¹, mar. 1996, pp. $1-27$.

BENATTI, Francesca; CARDOSO, Patrícia Silva. A garantia constitucional da propriedade privada como garantia de posições jurídicas: as experiências portuguesa e italiana. In: VEIGA, Fabio da Silva; GONÇALVES, Rubén Miranda. O Direito Constitucional e o seu papel na construção do cenário jurídico global. Barcelos: Portugal, 2016, pp. 49-58.

BENATTI, Francesca. Le situazioni di appartenenza in Cina: vecchie e nuove sfide. In: Rassegna di Diritto Civile. $n^{\circ}$. 1, 2015, pp. 207-229.

BERGER, Peter. The uncertain triumph of democratic capitalism. In: Journal of Democracy. vol. 3, $n^{\circ}$. 3, July 1992, p.52-64. Disponível em: < https://muse.jhu.edu/article/16659>. Acesso em: 03 abr. 2017.

BESLEY, Timothy. Property Rights and Investment Incentives: Theory and Evidence from Ghana. In: The Journal of Political Economy, vol. 103, n. 5, Oct., 1995, pp. 903-937.

BESLEY, Timothy. GHATAK, M. Property rights and economic development, In: RODRIK, Dani; ROSENZWEIG, Mark (eds.). Handbook of Development Economics. North-Holland: Elsevier BV, 2009.

BLACSTONE, William. Commentaries on the Law of England II, London: George Sharswood, 1809.

BRASIL. Seminário Internacional sobre a Proteção dos Direitos Econômicos e Sociais em tempos de crise econômica e o papel dos juízes. Conclusões. Disponível em: <http://www.stf.jus.br/arquivo/cms/noticiaNoticiaStf/anexo/CartaOuroPreto.pdf>. Acesso em: 04 mar. 2017.

BRITO, Miguel Nogueira de. Propriedade privada: entre o privilégio e a liberdade. Lisboa: FFMS, 2010. 
CANÇADO TRINDADE, Antônio Augusto. Dilemas e desafios da Proteção Internacional dos Direitos Humanos no limiar do século XXI. In: Revista Brasileira de Política Internacional. vol.40, $n^{\circ} .1,1997, \mathrm{pp}: 167-177$.

CONTI, Ricardo. Diritto di proprietà e CEDU. Itinerari giurisprudenziali europei. Viaggio fra Carte e Corti alla ricerca di un nuovo statuto proprietario. Brugini: Exeo Edizioni, 2012.

COMISSÃO DE VENEZA. Conference on the rule of law as a pratical concept. Lancaster House. London, 02 march 2012. Disponível em: <Disponível em: <http://www.venice.coe.int/webforms/documents/default.aspx?pdffile=CDL(2013)016-e>. Acesso em: 04 mar. 2017.

Draft checklist on the rule of law. Disponivel em: <http://www.venice.coe.int/webforms/documents/?pdf $=C D L(2016) 006-e>$. Acesso: 06 mar. 2017

Opinion $n^{\circ} .861 / 2016$. Amicus curiae brief for the constitutional Court on the restitution. Adopted by the Venice Commission at its 108 th Plenary Session. Venice, 14-15 October 2016. p. 02. Disponível em: http://www.venice.coe.int/webforms/documents/default.aspx?pdffile=CDLAD(2016)023-e. Acesso: 06 mar 2017.

Reporte sobre el Estado de Derecho, adoptado en su 86a sesión plenaria. Disponível em: $<$ http://www.venice.coe.int/webforms/documents/default.aspx?pdffile=CDL-AD(2011)003revspa>. Acesso em: 03 abr. 2017.

CONSELHO DA EUROPA. Comitê de Ministros. Disponível em: < http://www.coe.int/en/web/cm >. Acesso em: 28. mar. 2017.

Latin America. Recent Cooperation. Disponível em: < http://www.venice.coe.int/WebForms/pages/?p=03_Latin_America\&lang=EN >. Acesso em: 04 mar. 2017.

Gabinete de Documentação e Direito Comparado. Disponível em: <http://www.gddc.pt/cooperacao/materia-civil-comercial/conselho-europa.html>. Acesso em: 03 abr. 2017.

Estatuto. Disponível em: < www.gddc.pt/direitos-humanos/textos-internacionaisdh/tidhregionais/conv-tratados-05-05-949-ets-1.html >. Acesso em: 04 mar. 2017.

DEMSETZ, Harold. Toward a Theory of Property Rights. In: The American Economic Review, vol. 57, $n^{\circ}$. 2, Papers and Proceedings of the Seventy-ninth Annual Meeting of the American Economic Association, may, 1967.

DE SOTO, Hernando. II mistero del capitale. Milano: Garzanti, 2001.

ESTADOS UNIDOS DA AMÉRICA. Suprema Corte. Lynch v. Household Finance Corp., 405 U.S. 538, 552 (1972). Disponível em: < https://supreme.justia.com/cases/federal/us/405/538/>. Acesso em: 03 abr. 2017.

ESTRASBURGO. Carta de Direitos Fundamentais da União Europeia. Disponível em: < http://www.europarl.europa.eu/charter/pdf/text_pt.pdf >. Acesso em: 06 mar. 2017.

Corte Europeia de Direitos do Homem. Sttaford v. United Kingdon, de 28 de maio de 2002, parágrafo 63. Disponível em:

<http://swarb.co.uk/stafford-v-the-united-kingdom-echr-28-may-2002/>. Acesso em: 05 abr. 2017. 
Corte Europeia de Direitos do Homem. Manushaque Puto and Others against Albania and Driza against Albania (and 14 similar cases) group. General measures for the execution of the judgments of the European Court. Disponivel em: < https://rm.coe.int/CoERMPublicCommonSearchServices/DisplayDCTMContent?documentld=09 000016805ab71e>. Acesso em: 28. mar. 2017.

FERRAJOLI, Luigi. Diritti fondamentali, un dibattito teórico. Roma-Bari: Laterza, 2001.

FRIEDMAN, Milton. Capitalism and Freedom. Chicago: University of Chicago Press, 1962.

FRYE, Timothy. Credible commitment and Property Rights: Evidence from Russia. Disponível em: <http://www1.worldbank.org/publicsector/politicaleconomy/FryeCredibleCommitment.pdf/>.A cesso em: 03 abr. 2017.

FUKUYAMA, Francis. Capitalism \& Democracy: The missing link. In: Journal of Democracy, vol. 3, $n^{\circ}$. 3, July, 1992.

Capitalism \& Democracy: The missing link. In: Journal of Democracy, vol. 3, nº 3, July 1992, pp. 100-110. Disponível em: <https://muse.jhu.edu/article/225517/pdf>. Acesso em: 03 abr. 2017

Future of History: Can Liberal Democracy Survive the Decline of the Middle Class? In: Foreign Affairs, vol. 91, $\mathrm{n}^{\circ}$. 1, jan/febr., 2012, pp. 53-61. Disponível em: < http://www.jstor.org/stable/23217147>. Acesso em: 03 abr. 2017.

FRYE, Timothy. Original Sin, Good Works, And Property Rights in Russia. In: World Politics. n. 58, July 2006, pp. 479-504.

GAMBARO, Antonio. I beni, In: Trattato di Diritto Civile Commentato. diretto da Cicu-MessineoMengoni, continuato da P. Schlesinger, Milano: Giuffrè, 2012.

HELD, David. Models of Democracy. Cambridge/Malden: Polity Press, 2006.

HELFER, Laurence R. The New Innovation Frontier? Intellectual Property and the European Court of Human Rights. In: Harvard International Law Journal. Volume 49, n. 1, 2008, pp. 01-52.

HUNTINGTON, Samuel P. The Third Wave. Democratization in the Late Twentieth Century. Oklahoma: University of Oklahoma Press, 1993.

INDIA. SUPREMA CORTE. Lalaram \& Ors vs Jaipur Devt. Auth.\& Anr. on 1 December. Supreme Court of India. Disponível em: < https://indiankanoon.org/doc/168139441/>. Acesso em: 03 abr. 2017.

INKELES, Alex; DIAMOND, Larry. Personal Development and National Development: A CrossNational Perspectives. In: SZALAI, Alexander; ANDREWS, Frank M. (eds.). The Quality of Life: Comparative Studies, London: Sage Publications, 1980, pp. 73-109.

KAPSTEIN, Ethan B.; CONVERSE, Nathan. The Fate of Young Democracies. New York: Cambridge University Press, 2008; KAPSTEIN, Ethan B; CONVERSE, Nathan. Why democracies fail. In: Journal of Democracy, vol. 19, $n^{\circ}$. 4, October 2008, pp. 57-68.

Why Democracies Fail. In: Journal of Democracy, Volume 19, n. 4, October 2008. 
KELSEN, Hans. I fondamenti della democrazia. Bologna: II Mulino,1955.

KYUN-WON, Kim. Marx, Schumpeter and the East-Asian experience. In: Journal of Democracy, vol. 3, n. 3, July, 1992, pp. 17-31.

KURLANTZICK, Joshua. Democracy in retreat. The Revolt of The Middle Class and the Worldwide Decline of Representative Government. New Haven-London: Yale University Press, 2013.

LEBLANG, David A. Property Rights Democracy and Economic Growth. In: Political Research Quarterly, vol. 49, Issue 1, 1996, pp. 5-26.

LERNER, Daniel. The passing of traditional society, Glencoe: Free Press, 1958.

LIPSET, Seymour Martin. Some Social Requisites of Democracy: Economic Development and Political Legitimacy. In: The American Political Science Review. Volume 53, March 1959, pp. 69105.

Political Man. The Social Bases of Politics, New York: Doubleday \& Company, 1960, p. 41; WUCHERPFENNING, Julian; DEUTSCH, Franziska. Modernization and Democracy. Disponível em: < http://idwebhost-202-83.ethz.ch/index.php/Ird/article/viewFile/Ird-2009-4/14>. Acesso em: 03 abr. 2017.

LOCKE, John. Segundo Tratado Sobre o Governo Civil. Tradução: Magda Lopes e Marisa Lobo da Costa. São Paulo: Vozes, 2006.

MADISON, James. Property. In: National Gazette. March 29, 1792. Disponível em: <https://thf_media.s3.amazonaws.com/2011/pdf/FP_PS02.pdf >. Acesso em: 03 abr. 2017.

MAGRI, Geo. Quale futuro per la funzione sociale della proprietà? Abbandonare Weimar per tornare a Locke? BOCCONI LEGAL PAPERS, 2013. Disponível em: < http://works.bepress.com/bocconi_legal_papers/40>. Acesso em: 05 abr. 2017.

MINXIN PEI. Transition in China? More Likely than You Think. In: Journal of Democracy, vol. 27, $n^{\circ}$. 4, october.2016, pp. 5-19.

NORTH, Douglas C; THOMAS, Robert Paul. The Rise of the Western World: A New Economic History. New York: Cambridge University Press, 1973.

ODIHR and the rule of law. Disponível em: < http://www.osce.org/odihr/103448?download=true>. Acesso em: 08 abr. 2017. A Organização para a Segurança e Cooperação na Europa (OSCE) é uma organização de países do Ocidente voltada para a promoção da democracia e do liberalismo econômico na Europa.

OLSON, Mancur. Dictatorship, Democracy, and Development. In: The American Political Science Rev., vol. 87, $\mathrm{n}^{\circ}$. 3. Sep., 1993. Disponível em: <http://www.svt.ntnu.no/iss/Indra.de.Soysa/POL3503H05/olson.pdf>. Acesso em: 03 abr. 2017.

PRATA, Ana. A tutela constitucional da autonomia privada. Coimbra: Almedina, 2001. 
PRZEWORSKI, Adam; ALVAREZ, Michel; JCHIEBUB, Jose Antonio et al. Democracy and Development: Political Institutions and Well-Being in the World, 1950-1990. Cambridge: Cambridge University Press, 2000.

PRZEWORSKI, Adam; LIMONGI, Fernando. Political Regimes and Economic Growth. In: The Journal of Economic Perspectives. vol. 7, n. 3, 1993, pp. 51-69.

PUGLIATTI, Salvatore. La proprietà nel nuovo diritto. Milano: Giuffrè, 1954.

ROMA. Convenção para a Proteção dos Direitos do Homem e das Liberdades Fundamentais. Disponível em: < http://www.echr.coe.int/Documents/Convention_POR.pdf>. Acesso em: 04 mar. 2017.

ROWEN, Henry. The tide underneath the 'third wave'. In: Journal of Democracy. vol. $6, \mathrm{n}^{\circ} 1$, January 1995, pp. 52-64. Disponível em:< https://muse.jhu.edu/article/16659>. Disponível em: 08 abr. 2017.

SINGER, Joseph W. Property as the law of Democracy, In: Duke Law Journal, vol. 63, n. 6, 2014, pp. 1287-1355.

SINGER, Joseph W. LIMONGI, Fernando. Political Regimes and Economic Growth. In: The Journal of Economic Perspectives, vol. 7, nº 3, 1993.

SMITH, Adam. An Inquiry into the Nature and Origins of the Wealth of Nations, New York: Edwin Cannan MA. LLD, 1937.

SCHUMPETER, Joseph A. Capitalism, Socialism and Democracy. New York \& London: George Allen \& Unwin Publishers, 2011.

WUCHERPFENNING, Julian; DEUTSCH, Franziska. Modernization and Democracy: Theories and Evidence Revisited. In: Living Reviews in Democracy. 2009. pp. 01-09.

Trabalho enviado em 14 de abril de 2017.

Aceito em 25 de abril de 2017. 